\title{
HCN2 and HCN1 Channels Govern the Regularity of Autonomous Pacemaking and Synaptic Resetting in Globus Pallidus Neurons
}

\author{
C. Savio Chan, ${ }^{1,2}$ Ryuichi Shigemoto, ${ }^{2,3}$ Jeff N. Mercer, ${ }^{1}$ and D. James Surmeier ${ }^{1}$ \\ ${ }^{1}$ Department of Physiology and Institute for Neuroscience, Feinberg School of Medicine, Northwestern University, Chicago, Illinois 60611, ${ }^{2}$ Division of \\ Cerebral Structure, National Institute for Physiological Sciences, Okazaki 444-8787, Japan, and ${ }^{3}$ Core Research for Evolutional Science and Technology, \\ Japan Science and Technology Corporation, Kawaguchi, Saitama 332-0012, Japan
}

\begin{abstract}
The globus pallidus (GP) is a critical component of the basal ganglia circuitry controlling motor behavior. Dysregulation of GP activity has been implicated in a number of psychomotor disorders, including Parkinson's disease (PD), in which a cardinal feature of the pathophysiology is an alteration in the pattern and synchrony of discharge in GP neurons. Yet the determinants of this activity in GP neurons are poorly understood. To help fill this gap, electrophysiological, molecular, and computational approaches were used to identify and characterize GABAergic GP neurons in tissue slices from rodents. In vitro, GABAergic GP neurons generate a regular, autonomous, single-spike pacemaker activity. Hyperpolarization-activated, cyclic nucleotide-gated cation (HCN) channels make an important contribution to this process: their blockade with ZD7288 significantly slowed discharge rate and decreased its regularity. HCN currents evoked by somatic voltage clamp had fast and slow components. Single-cell RT-PCR and immunohistochemical approaches revealed robust expression of $\mathrm{HCN} 2$ subunits as well as significant levels of $\mathrm{HCN} 1$ subunits in GABAergic GP neurons. Transient activation of striatal GABAergic input to GP neurons led to a resetting of rhythmic discharge that was dependent on HCN currents. Simulations suggested that the ability of transient striatal GABAergic input to reset pacemaking was dependent on dendritic HCN2/HCN1 channels. Together, these studies show that HCN channels in GABAergic GP neurons are key determinants of the regularity and rate of pacemaking as well as striatal resetting of this activity, implicating HCN channels in the emergence of synchrony in PD.
\end{abstract}

Key words: basal ganglia; pacemaking; rhythmicity; cation channel; patch clamp; single-cell RT-PCR; brain slice; ZD7288; cesium; sodium channel; HCN; Ih

\section{Introduction}

The rodent globus pallidus (GP) [and its primate equivalent, the external segment of globus pallidus (GPe)] is a key component of the basal ganglia circuitry controlling movement. Anatomical and electrophysiological work has revealed that the GP is richly interconnected with all of the other major elements in the basal ganglia macrocircuit (Bevan et al., 2002). Because of its broad connectivity, aberrant activity patterns in GP neurons can have far-reaching consequences for basal ganglia function.

In vivo, GP neurons display a tonic, high-frequency discharge that is interrupted by pauses (DeLong, 1971; Bergstrom and Walters, 1981; Filion and Tremblay, 1991; Filion et al., 1991; Magill et al., 2001). The tonic "background" activity in GP neurons was originally thought to be dependent on a maintained

Received June 3, 2004; revised Sept. 20, 2004; accepted Sept. 22, 2004.

This work was supported by the Morris K. Udall Parkinson's Disease Research Center of Excellence (National Institute of Neurological Disorders and Stroke Grant P50 NS047085) (D.J.S.). We thank Karen P. Burnell and Qing Ruan for excellent technical assistance and Wendy W. Wu for helpful discussion.

Correspondence should be addressed to Dr. D. James Surmeier, Department of Physiology, Feinberg School of Medicine, Northwestern University, 303 East Chicago Avenue, Searle 5-447, Chicago, IL 60611. E-mail: j-surmeier@northwestern.edu.

DOI:10.1523/JNEUROSCI.2162-04.2004

Copyright $\odot 2004$ Society for Neuroscience $\quad$ 0270-6474/04/249921-12\$15.00/0 excitatory synaptic input arising from the subthalamic nucleus (STN) (Kita and Kitai, 1987; Parent and Hazrati, 1995). Although synaptic input from STN neurons may accelerate GP discharge, in vitro studies have shown that presumed GP projection neurons are capable of autonomous, pacemaker activity (Nambu and Llinas, 1994, 1997; Cooper and Stanford, 2000; Stanford, 2003). Despite the fact that GP neurons do not depend on synaptic input to maintain spiking, the pauses seen in vivo do appear to depend on GABAergic synaptic input arising from striatal and intrapallidal sources (Nakanishi et al., 1985; Kita and Kitai, 1991; Nambu and Llinas, 1994; Cooper and Stanford, 2000; Stanford, 2003).

In animal models of Parkinson's disease (PD) and in patients, this activity pattern changes. Correlated, rhythmic burst discharge emerges in GP neurons (Filion and Tremblay, 1991; Nini et al., 1995; Bergman et al., 1998; Magnin et al., 2000; Raz et al., 2000, 2001). The GP pathophysiology is correlated with the appearance of motor deficits, fueling speculation that the altered activity of GP neurons is responsible. The origin of the rhythmic bursting in GP neurons has not been determined experimentally, but modeling work points to an interaction between intrinsic properties and the synaptic linkages with the striatum and the STN (Terman et al., 2002).

One of the channels expressed by presumptive GP projection 
neurons that could be at the center of this interaction is the hyperpolarization-activated, cyclic nucleotide-gated cation (HCN) channel. These channels support pacemaking in various excitable cell types (McCormick and Pape, 1990; Maccaferri et al., 1996; Neuhoff et al., 2002). Because they are located primarily in dendrites, they are also in a position to sculpt synaptic responses (Lorincz et al., 2002). The clearest evidence for this role of HCN channels comes from an examination of dendritic integration of EPSPs (Magee, 1998, 1999; Williams and Stuart, 2000; Berger et al., 2001), but they undoubtedly influence how neurons respond to dendritic GABAergic inputs as well (Williams and Stuart, 2003). Sculpting of this type could determine how GP neurons respond to striatal GABAergic input. Indeed, the studies described here show that these channels (1) determine the rate and regularity of autonomous pacemaking in GP neurons and (2) sculpt the response to striatal GABAergic input, allowing this input to reset pacemaking, thus creating a synchronizing mechanism of potential relevance to $\mathrm{PD}$.

\section{Materials and Methods}

Animals. Male and female C57BL/6 mice (Harlan, Indianapolis, IN) aged postnatal day 17-22 were used. The handling of mice and all procedures performed on them were approved by the Northwestern University's Animal Care and Use Committee and were in accordance with the $\mathrm{Na}$ tional Institutes of Health Guide to the Care and Use of Laboratory Animals. All efforts were made to minimize the number of animals used and the suffering of those killed.

Slice preparation. Animals were anesthetized with isoflurane and decapitated. Brains were removed rapidly and placed immediately in icecold artificial CSF (ACSF) containing (in $\mathrm{mm}$ ): $125 \mathrm{NaCl}, 2.5 \mathrm{KCl}, 1$ $\mathrm{MgCl}_{2}, 2 \mathrm{CaCl}_{2}, 1.25 \mathrm{NaH}_{2} \mathrm{PO}_{4}, 13$ glucose, and $25 \mathrm{NaHCO}_{3}$, bubbled continuously with carbogen $\left(95 \% \mathrm{O}_{2}\right.$ and $\left.5 \% \mathrm{CO}_{2}\right)$. Thin hemicoronal or sagittal slices $(250 \mu \mathrm{m})$ containing the GP were made using a vibrating microtome (VT-1000s; Leica Instrument, Leitz, Nussloch, Germany) and equilibrated in ACSF for at least $1 \mathrm{hr}$ before recording.

Electrophysiological recording and synaptic stimulation in slices. Slices were transferred to a small volume $(<0.5 \mathrm{ml})$ recording chamber that was mounted on a fixed-stage, upright microscope (BX51; Olympus, Melville, NY) equipped with IR-DIC [0.9 numerical aperture (NA)] (Olympus, Tokyo, Japan). The recording chamber was superfused with carbogen-saturated ACSF with a flow rate of $1.5-2 \mathrm{ml} / \mathrm{min}$. Experiments were performed at room temperature unless specified otherwise. Neuronal somata and proximal dendrites were visualized by videomicroscopy at high magnification $(60 \times, 0.9$ NA water immersion objective; Olympus) with a back-thinned, frame-transfer cooled-CCD camera (Micromax EBFT512; Roper Scientific, Trenton, NJ) aided by a contrast enhancement system (Argus-20; Hamamatsu Photonics, Hamamatsu City, Japan). Conventional tight-seal (>3 G $\Omega$ ) whole-cell patch-clamp and cell-attached recordings were made on visually identified, putative GP output neurons, based on size and somatodendritic morphology. Only neurons in the rostral to midlevel GP were studied (ShammahLagnado et al., 1996). The neuronal phenotype was verified using singlecell RT-PCR (scRT-PCR) profiling for the $67 \mathrm{kDa}$ isoforms of glutamate decarboxylase (GAD67) and choline acetyltransferase (ChAT) and by spiking pattern (Bengtson and Osborne, 2000). These indices were very consistent and provided a reliable means of identifying neurons. As a consequence, scRT-PCR profiling was discontinued for routine cellular identification in later experiments (see below).

Patch electrodes ( $1.5 \mathrm{~mm}$ outer diameter) were fabricated from filamented, thick-wall borosilicate-glass (Sutter Instruments, Novato, CA) pulled on a Flaming-Brown puller (P-97; Sutter Instruments). Pipette resistance was typically near $3 \mathrm{M} \Omega$ when filled with recording solution. The recording internal solution consisted of (in mM): $140 \mathrm{KMeSO}_{4}, 5.0$ EGTA, 0.1 $\mathrm{CaCl}_{2}, 2.0 \mathrm{Mg}$-ATP, $4.0 \mathrm{Na}_{3}$-GTP, 10 HEPES, pH 7.25-7.30, $280 \mathrm{mOsm} . \mathrm{MeSO}_{4}$ was used rather than gluconate (Cooper and Stanford, 2000) because of reports that gluconate blocks calcium-activated potassium conductances that might contribute to the autonomous activ-
Table 1. The kinetic structure of each channel model is from Wang et al. (2002) with the rate constants $\alpha_{0^{\prime}}, \beta_{0}, \alpha_{A}$ and $\beta_{A}$ defined by $r(V)=r_{0} /(1+\exp [-\{V-$ $V_{1 / 2}-V_{\text {shift }}$ s] $]$ ); specifically, in our model:

\begin{tabular}{clllr}
\hline & $r_{0}\left(\mathrm{msec}^{-1}\right)$ & $V_{1 / 2}(\mathrm{mV})$ & $V_{\text {shift }}(\mathrm{mV})$ & $s\left(\mathrm{mV}^{-1}\right)$ \\
\hline $\mathrm{HCN} 1 / 2$ & & & & \\
$\alpha_{0}$ & 0.006 & -96 & -2 & -0.155 \\
$\beta_{0}$ & 0.0008 & -51.7 & -2 & 0.144 \\
$\alpha_{\mathrm{A}}$ & 0.0006 & -94.2 & -2 & -0.075 \\
$\beta_{\mathrm{A}}$ & 0.004 & -35.5 & -2 & 0.144 \\
$\mathrm{HCN} 2$ & & & & \\
$\alpha_{0}$ & 0.0009 & -95 & -12 & -0.12 \\
$\beta_{0}$ & 0.0004 & -51.7 & -12 & 0.12 \\
$\alpha_{\mathrm{A}}$ & $3 \times 10^{-5}$ & -94.2 & -12 & -0.075 \\
$\beta_{\mathrm{A}}$ & 0.001 & -35.5 & -12 & 0.144 \\
\hline
\end{tabular}

ity. In some experiment, $0.1-0.2 \%$ biocytin was added to the patch solution. The liquid junction potential in our recording ACSF was $\sim 7 \mathrm{mV}$ and not corrected for.

Data were obtained via a MultiClamp 700A amplifier (Axon Instruments, Foster City, CA) interfaced to a Pentium-based PC running pClamp8.2 (Axon Instruments). The signal was filtered at $1-4 \mathrm{kHz}$ and digitized at $5-20 \mathrm{kHz}$ with a Digidata $1322 \mathrm{~A}$ (Axon Instruments). For current-clamp recordings, the amplifier bridge circuit was adjusted to compensate for electrode resistance and monitored. Electrode capacitance was also compensated. In somatic point voltage-clamp recordings, series resistance was measured but not compensated; given the small amplitude of the HCN currents, this should have produced an error of only $1-2 \mathrm{mV}$. If series resistance increased $>20 \%$ during recording, the data were discarded.

Electrical stimuli were delivered using an isolated stimulator (Digitimer, Welwyn Garden City, UK). Striatal inhibitory inputs were stimulated at $20 \mathrm{~Hz}$, with a concentric bipolar electrode (FHC, Bowdoinham, $\mathrm{ME})$ placed in the striatum according to the topography of the striatalpallidal projection. Stimulus intensities were adjusted to the lowest level that reliably evoked synaptic responses. Trains of pulses were delivered at intervals of $>20 \mathrm{sec}$ to allow full recovery of synaptic processes. Glutamatergic synaptic transmission was blocked by adding 6-cyano-7nitroquinoxaline-2,3-dione (CNQX; $20 \mu \mathrm{M}$ ) and D-(-)-2-amino-5phosphonopentanoic acid (APV; $50 \mu \mathrm{M})$ to the ACSF. The resultant synaptic responses were abolished by bicuculline methiodide $(10 \mu \mathrm{M})$ or SR95531 $(10 \mu \mathrm{M})$, demonstrating that they were $\mathrm{GABA}_{\mathrm{A}}$ receptor mediated.

Data analysis and statistics methods. Curve fitting (using a least-squares criterion) and data analysis were done with Igor Pro 5.0 (WaveMetrics, Lake Oswego, OR). Numerical data are expressed and sample statistics are given as mean $\pm \mathrm{SE}$ (for samples $\geq 10$ ) or median (interquartile range), for smaller samples. Box plots were used for graphic presentation of the data because of the small sample sizes. In data presented as box plots, the central line represents the median, the edges of the box represent the interquartile range, and the "whisker lines" show the extent of the overall distribution, excluding outliers (points $>1.5 \pm$ intraquatrile range), which are shown as circles. Small, nonmatched samples were analyzed with nonparametric Kruskal-Wallis ANOVA, using a probability $(p)$ threshold of 0.05 .

Computer simulation and modeling. Simulations were performed using NEURON (version 5.4) (Hines and Carnevale, 1997). To model currents generated from somatic point-clamp recordings, allosteric models of $\mathrm{HCN} 2$ and $\mathrm{HCN} 2 / \mathrm{HCN} 1$ heteromeric channels were derived from published work (Chen et al., 2001). As in these descriptions, the models used a simplified four-state kinetic description that accounts for the modulating properties of cyclic nucleotide binding. The forward and backward rate constants for the HCN model are listed on Table 1. NEURON mod files containing these descriptions are available on request. Based on anatomical observation (Iwahori and Mizuno, 1981; Park et al., 1982; Millhouse, 1986), GP neurons were modeled using a spherical soma (20 $\mu \mathrm{m}$ radius) connected to four dendrites. Each dendrite had two compartments: a proximal cylinder of $200 \mu \mathrm{m}$ (diameter $2 \mu \mathrm{m}$ ) connected to 
a secondary cylinder of $150 \mu \mathrm{m}$ in length and having a diameter of $1 \mu \mathrm{m}$. Specific membrane resistivity $(\infty)$, capacitance $\left(1 \mu \mathrm{F} / \mathrm{cm}^{2}\right)$, and axial resistivity $(70 \mathrm{ohm}-\mathrm{cm})$ were the same for all compartments and similar to previous simulation (Hanson et al., 2004). A somatic voltage clamp was "attached" to the model using series resistance estimates derived from recordings ( $6 \mathrm{M} \Omega$ ). HCN current traces generated experimentally by somatic voltage steps delivered to GP neurons in tissue slices were imported from Igor Pro to the NEURON Multi-Run Fitter (MRF). The MRF was allowed to control the density of HCN2/HCN1 and HCN2 channels in the proximal and distal compartments. This approach led to a reasonably accurate simulation of the experimental data and an estimate of the relative density of $\mathrm{HCN} 1 / \mathrm{HCN} 2$ and HCN2 channels in the dendritic compartments. These relative densities were used to estimate the ability of GABAergic synaptic events to activate each channel type. A more complete model of GP neuron spiking was constructed by adding channels known to be important to the spiking of GP neurons; mod files for $\mathrm{Na}^{+}, \mathrm{Kv} 1, \mathrm{Kv} 2, \mathrm{Kv} 3, \mathrm{Kv} 4$, and Kv7 (KNCQ) channels were constrained by experimental data (Baranauskas et al., 1999; Tkatch et al., 2000; Baranauskas et al., 2003) and incorporated. These mod files are available on request. The model produced autonomous spiking near 10 $\mathrm{Hz}$ with a membrane potential trajectory that strongly resembled experimentally recorded potentials. A voltage noise was added (uniformly distributed) to introduce interval irregularities like those seen experimentally. Inhibitory synaptic events were then generated in either the distal dendritic compartment or the soma, and the impact on autonomous discharge was compared with experimentally derived records.

Tissue and scRT-PCR analysis. In some experiments, neurons were aspirated after whole-cell recording in the slice for mRNA profiling. Because of incomplete mRNA harvesting with this approach, in another set of experiments GP neurons were acutely dissociated using procedures similar to those that we have described previously (Baranauskas et al., 1999). Acutely isolated neurons were aspirated into sterilized glass pipettes containing nominally RNase-free patch solution or diethylpyrocarbonate-treated water and $0.8 \mathrm{U} / \mu \mathrm{l}$ SUPERase-In (Ambion, Austin, TX). Sterile gloves were worn during the procedure to minimize RNase contamination. After aspiration, the contents of the pipette were ejected into $0.6 \mathrm{ml}$ presiliconized tubes (Midwest Scientific, Valley Park, MO) containing a reverse transcription mix. This mix contained $0.7 \mu \mathrm{l}$ of Superase-IN $(20 \mathrm{U} / \mu \mathrm{l}), 1.9 \mu \mathrm{l}$ of diethylpyrocarbonate-treated water, 1 $\mu \mathrm{l}$ of dNTPs $(10 \mathrm{~mm}), 0.7 \mu \mathrm{l}$ of BSA $(143 \mu \mathrm{g} / \mu \mathrm{l})$, and $0.7 \mu \mathrm{l}$ of oligo-dT $(0.5 \mu \mathrm{g} / \mu \mathrm{l})$. Together with cell contents, the mixture was heated to $65^{\circ} \mathrm{C}$ for $5 \mathrm{~min}$ to linearize mRNA and then placed on ice for at least $1 \mathrm{~min}$. Single-strand cDNA was synthesized from the cellular mRNA by adding $2 \mu \mathrm{l}$ of $10 \times$ PCR buffer, $4 \mu \mathrm{l}$ of $\mathrm{MgCl}_{2}(25 \mathrm{~mm}), 2 \mu \mathrm{l}$ of DTT $(0.1 \mathrm{M}), 1 \mu \mathrm{l}$ of RNase out $(40 \mathrm{U} / \mu \mathrm{l})$, and $6 \mu \mathrm{l}$ of diethylpyrocarbonate-treated water. This mixture was then incubated at $42^{\circ} \mathrm{C}$ for 2 min. After the initial incubation, $0.7 \mu \mathrm{l}$ of Superscript II $(50 \mathrm{U} / \mu \mathrm{l})$ was added, and the mixture was kept at $42^{\circ} \mathrm{C}$ for an additional $50 \mathrm{~min}$. The reaction was terminated by heating to $70^{\circ} \mathrm{C}$ for $15 \mathrm{~min}$. The RNA strand in the RNA-DNA hybrid was then removed by adding $0.5 \mu \mathrm{l}$ of RNase $\mathrm{H}(2 \mathrm{U} / \mu \mathrm{l})$ and incubating at $37^{\circ} \mathrm{C}$ for $20 \mathrm{~min}$. All reagents except Superase-IN (Ambion) were obtained from Invitrogen (Gaithersburg, MD).

Single-cell cDNA was amplified using a conventional PCR approach with a programmable thermal cycler (MJ Research, Watertown, MA). PCR primers were developed from GenBank sequences with commercially available OLIGO 6.7.1 software (National Biosciences, Plymouth, $\mathrm{MN}$ ). Primers and reaction protocols for ChAT, GAD67, parvalbumin (PV), enkephalin (ENK), and HCN1-4 have been described previously (Surmeier et al., 1996; Song et al., 1998; Tkatch et al., 1998; Franz et al., 2000). After amplification, PCR products were labeled by ethidium bromide and separated by electrophoresis on agarose gels. Amplicons were of the expected size and sequence.

RT-PCR was performed using procedures designed to minimize the chance of cross-contamination (Cimino et al., 1990). Negative controls for contamination from extraneous DNA were run for every batch of neurons. Contamination from extraneous sources was checked by eliminating the cellular template for one reverse transcript reaction. The controls were consistently negative in these experiments.

Immunohistochemistry. C57BL/6 mice and Sprague Dawley rats (Har- lan) were used for the immunohistochemistry using methods as described previously (Notomi and Shigemoto, 2004). Two HCN1 antibodies $\left(\mathrm{N}_{2} 2_{850-910}\right.$ and $\mathrm{HCN1}_{6-24}$; Alomone Laboratories, Jerusalem, Israel) that were raised against nonoverlapping epitopes and an HCN2 (N21 $1_{797-862}$ ) antibody were used in the present study. The specificity of the antibodies have been characterized previously (Lorincz et al., 2002; Holderith et al., 2003; Notomi and Shigemoto, 2004). In brief, animals aged postnatal day 17-22 were anesthetized deeply (sodium pentobarbital, $60 \mathrm{mg} / \mathrm{kg}$, i.p.) and perfused transcardially first with $0.9 \%$ saline followed by ice-cold fixative containing $4 \%$ paraformaldehyde, $15 \%$ saturated picric acid in $0.1 \mathrm{M}$ phosphate buffer, $\mathrm{pH}$ 7.3-7.4. Tissue blocks containing the GP were cryoprotected in $30 \%$ sucrose in $0.1 \mathrm{M} \mathrm{PB}$ overnight at $4^{\circ} \mathrm{C}$. Sections were cut on a sliding microtome at a thickness of 40 $\mu \mathrm{m}$ and incubated with $0.2-1.0 \mu \mathrm{g} / \mathrm{ml}$ antibodies for HCN1 and HCN2 in PBS containing $10 \%$ normal goat serum (NGS) and $0.1 \%$ Triton $\mathrm{X}-100(\mathrm{Tx})$ for $24 \mathrm{hr}$ at $4^{\circ} \mathrm{C}$. After washes in PBS, the sections were incubated (at room temperature for $2 \mathrm{hr}$ ) with biotinylated donkey antiguinea pig or anti-rabbit IgGs (Jackson ImmunoResearch Laboratories, West Grove, PA) diluted 1:200 in PBS-Tx containing 1\% NGS. The sections were then washed and reacted with avidin-biotin peroxidase complex (ABC-Elite kit; Vector Laboratories, Burlingame, CA) at room temperature for $2 \mathrm{hr}$. Bound peroxidase enzyme activity was revealed using Tris-buffered saline, $\mathrm{pH} \quad 7.3$, containing $0.025 \% \quad 3-3-$ diaminobenzidine tetrahydrochloride (Sigma, St. Louis, MO), $0.05 \%$ nickel chloride, and $0.003 \%$ hydrogen peroxide. The pattern of immunoreactivity was similar in both species of rodents. No specific immunostaining for respective molecules was observed (data not shown) because sections were incubated with the omission of each of the primary antibodies.

Reagents and channel ligands. All reagents were obtained from Sigma except $\mathrm{KMeSO}_{4}$ (ICN Biomedicals Aurora, $\mathrm{OH}$ ), $\mathrm{Na}_{2}$-GTP (Boehringer Mannheim, Indianapolis, IN), bicuculline methiodide, SR95531, ZD7288 (Tocris Cookson, Ballwin, MO), and TTX (Alomone Laboratories). Drugs were dissolved as stock solutions in either water or DMSO and aliquoted and frozen at $-30^{\circ} \mathrm{C}$ before use. Each of the drugs was diluted in the perfusate immediately before the experiment. When used, the final concentration of DMSO was always $<0.1 \%$.

\section{Results}

\section{GABAergic GP projection neurons are fast spiking}

Previous electrophysiological studies have identified several different cell types within the anatomical confines of the GP (Kita and Kitai, 1991; Nambu and Llinas, 1994, 1997; Cooper and Stanford, 2000; Poisik et al., 2003). Anatomical and histochemical work have shown that this heterogeneity can be explained in part by the presence of neurons that are properly considered to be part of the basal forebrain cholinergic cell group (Zaborszky et al., 1999; Bengtson and Osborne, 2000). These neurons are distinguished by their expression of ChAT. GP projection neurons, on the other hand, are GABAergic (Oertel et al., 1984; Mercugliano et al., 1992; Smith et al., 1998). Two subpopulations of GABAergic GP neurons have been distinguished on the basis of PV and ENK expression (Kita, 1994; Rajakumar et al., 1994; Hontanilla et al., 1998; Hoover and Marshall, 1999; Voorn et al., 1999; Kita and Kita, 2001).

To ensure that our sample was restricted to GP projection neurons, scRT-PCR techniques were used to profile mediumsized neurons with multipolar or triangular somata from the rostral GP for their expression of ChAT, GAD, PV, and ENK. These neurons consistently expressed GAD but not ChAT mRNA (Fig. 1C). Some of these neurons had detectable levels of PV mRNA, whereas others had readily detectable levels of ENK mRNA. These GABAergic GP neurons fired at high frequency with little or no accommodation in response to a depolarizing current injection. They also exhibited characteristic slowly developing, time-dependent inward rectification when injected with hyper- 

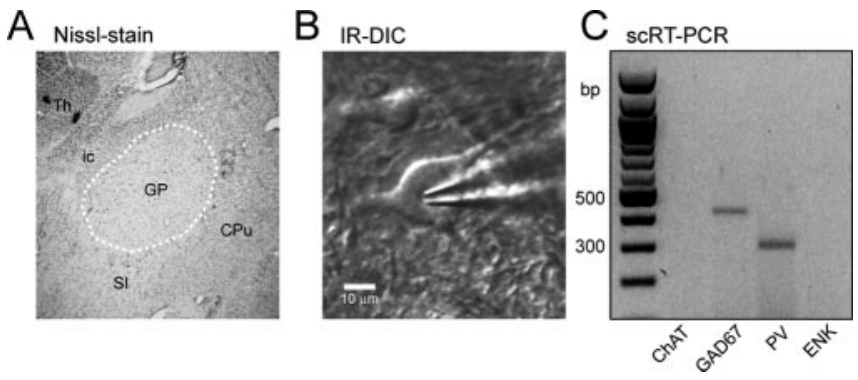

Figure 1. Identification of GABAergic GP neurons. A, A coronal (Nissl-stained) mouse brain section that contained mid-rostral GP. It is sandwiched between the curve of the lateral caudate-putamen ( $\mathrm{CPu}$ ) and the medial internal capsule (ic). The low density of GP neurons gives the nucleus a very distinctive, pale appearance. $B$, Visualized whole-cell recordings were made with contrast-enhanced IR-DIC videomicroscopy (middle panel). C, Phenotyping was done on a subset of neurons, verifying that they expressed GAD67 and PV or ENK.

polarizing current steps. Within this population of identified neurons, there were not obvious subtypes. Larger neurons with anatomical features resembling those of type I neurons (Nambu and Llinas, 1997) were recorded from occasionally. As in previous descriptions, these neurons were not spontaneously active, had relatively hyperpolarized resting membrane potentials (more than $-65 \mathrm{mV}$ ), and displayed membrane properties resembling basal forebrain cholinergic neurons (Bengtson and Osborne, 2000). ScRT-PCR profiling confirmed that these neurons expressed ChAT (data not shown).

\section{GABAergic GP neurons are autonomous pacemakers}

All GP neurons $(n=78)$ with phenotypic properties of GABAergic projection neurons were spontaneously active in both cellattached and whole-cell recording (Fig. 2A), despite the fact that their excitatory synaptic input from the STN was severed in the preparation of the slice. To ensure that the remaining glutamatergic connections were not contributing to the observed activity, glutamatergic synaptic transmission was blocked with the addition of CNQX $(20 \mu \mathrm{M})$ and APV $(50 \mu \mathrm{M})$. These receptor antagonists had no effect on the discharge rate or pattern of GP neurons ( $n=3$; data not shown). This finding is in agreement with previous work showing a subtype of GP neuron to be autonomously active (Nambu and Llinas, 1994; Cooper and Stanford, 2000). To determine whether GABAergic synaptic input was significantly slowing the autonomous discharge of these neurons, $\mathrm{GABA}_{\mathrm{A}}$ receptors were blocked with bicuculline or SR95531 (10 $\mu \mathrm{M})$ (Ueno et al., 1997). Again, there was no obvious change in the discharge rate or pattern of GP neurons after the elimination of $\mathrm{GABA}_{\mathrm{A}}$ receptor activity $(p>0.05$; Kruskal-Wallis ANOVA; $n=6$; data not shown).

The autonomous, ongoing spike activity of GP projection neurons was very regular. In whole-cell recordings, GP neurons discharged at $\sim 12 \mathrm{~Hz}$ (mean frequency $=12.5 \pm 0.4 \mathrm{~Hz}$; $20-22^{\circ} \mathrm{C} ; n=65$ ) with a coefficient of variation (CV) of 0.18 $( \pm 0.01 ; n=65$ ) (Fig. $2 A, B)$. Injecting hyperpolarizing current slowed the discharge rate, until discharge stopped altogether (Fig. $2 A)$. Autocorrelograms of GP neuronal discharge near the mean rate typically revealed a long-range periodic structure (Fig. $2 B$ ). There was no relationship between discharge rate and $\mathrm{CV}$ (Fig. 2C).

Previous work has suggested that TTX-sensitive $\mathrm{Na}^{+}$currents are responsible for autonomous activity (Nambu and Llinas, 1994; Stanford, 2003). To verify that this was true of GABAergic GP neurons, TTX $(1 \mu \mathrm{M})$ was applied while pacemaking was recorded. As expected, TTX completely abolished spiking with-

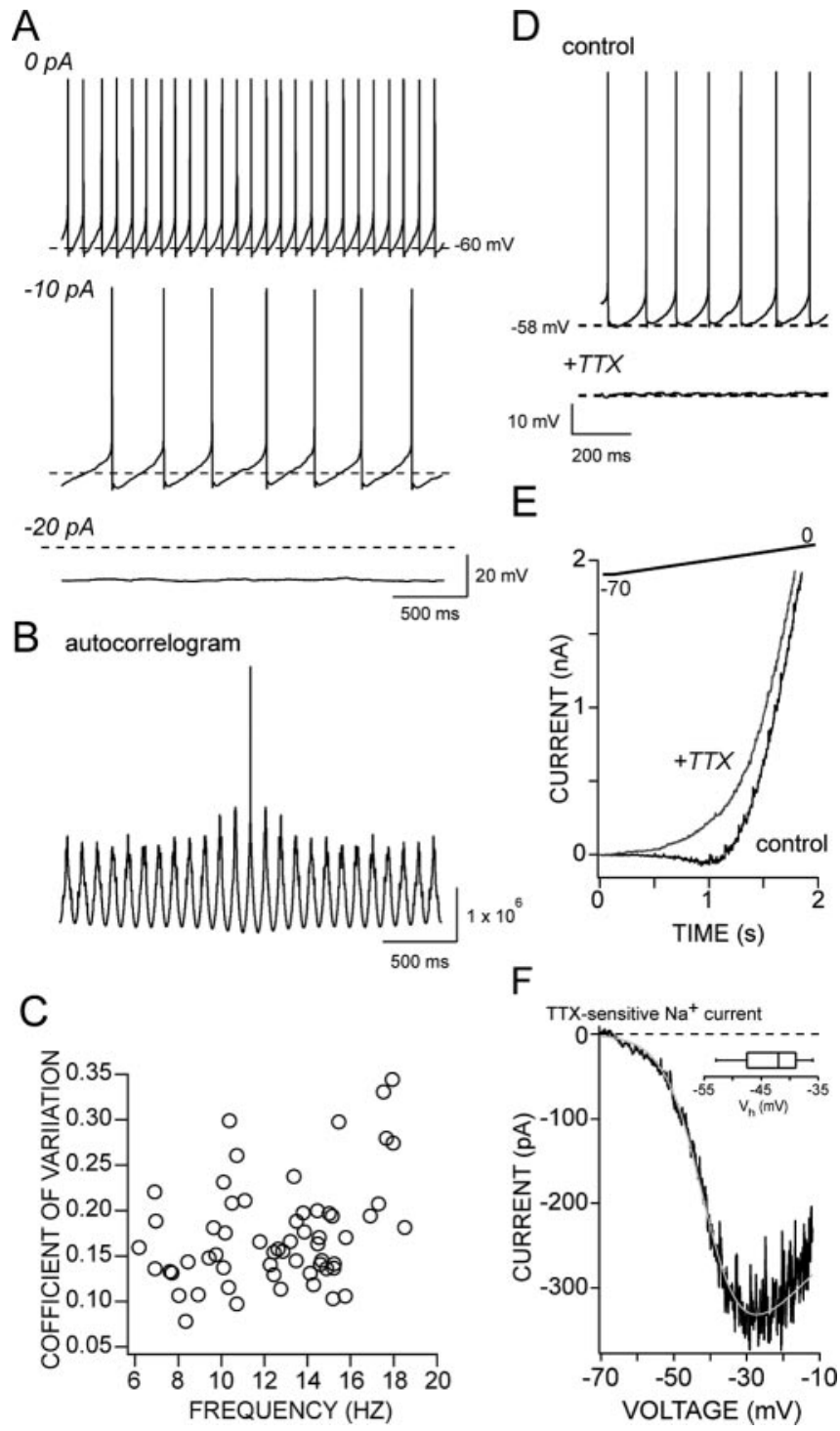

Figure 2. Autonomous pacemaking in GP neurons is dependent on TTX-sensitive $\mathrm{Na}^{+}$channels. A, Whole-cell current-clamp recording of a pacemaking GP neuron. Progressive hyperpolarizing current injection slowed and then stopped spiking without revealing subthreshold oscillations. $B$, Autocorrelation of action potential trains from the corresponding recordings in $A$, with $0 \mathrm{pA}$ current injection revealing the highly regular discharge of the neuron. $C$, There was no discernible relationship between the discharge rate and the regularity of discharge as revealed by the CV.D, Blockade of voltage-dependent $\mathrm{Na}{ }^{+}$channel with $\operatorname{TTX}(1 \mu \mathrm{M})$ abolished repetitive firing of GP neurons and revealed the absence of subthreshold oscillation. $E$, Ramping the somatic membrane potential from -70 to $0 \mathrm{mV}$ revealed a TTX-sensitive region of negative slope conductance. $F$, "Persistent" sodium current was isolated by subtracting ramp current in the presence and absence of TTX $(1 \mu \mathrm{m})$; note that it was prominent at subthreshold potentials. White line represents the best fitting to the current trace with an extended Boltzmann function as follows: $I=A /\left\{\left[1+\exp \left[\left(V_{\mathrm{m}}-V_{1 / 2}\right) / k\right)\right]\right\} \cdot\left(V_{\mathrm{m}}-V_{\mathrm{Na}}\right)$, where $V_{\mathrm{Na}}$ is the reversal potential of sodium current. The fitting parameters are $V_{\mathrm{h}}=-41.4 \mathrm{mV}, k=5.1$. Inset is a box plot of the same of cells analyzed in this way; the median $V_{\mathrm{h}}$ is $-42.0 \mathrm{mV}(n=4)$.

out revealing an underlying oscillation $(n=6)$ (Fig. $2 D)$. To gain a better picture of the $\mathrm{Na}^{+}$currents underlying this activity, neurons were subjected to slow voltage ramps from -80 to $0 \mathrm{mV}$ (Fig. 2E). The TTX-sensitive current evoked by this protocol began to be noticeable above $-70 \mathrm{mV}$ and peaked near $-30 \mathrm{mV}$ (Fig. $2 E, F$ ). Although there are obvious space-clamp limitations to these experiments, it is clear that TTX-sensitive current creates a negative slope conductance region in GABAergic GP neurons, as required for pacemaking. 


\section{Low-voltage-activated calcium current is not involved in} pacemaking of mouse GP neurons

In some neurons, low-voltage-activated (T-type) calcium current contributes to the generation of rhythmic activity (Huguenard, 1996; McCormick and Bal, 1997; Wolfart and Roeper, 2002). Although previous voltage-clamp experiments by our group failed to detect T-type $\mathrm{Ca}^{2+}$ channels in acutely isolated GABAergic GP neurons (Surmeier et al., 1994), it is possible that these channels are dendritic and lost in this preparation. To test this conclusion in the tissue slice where dendrites are intact, the ability of mibefadil to alter pacemaking was examined; mibefradil is the most selective blocker of Cav3 family channels currently available (McDonough and Bean, 1998; Todorovic and Lingle, 1998; Martin et al., 2000; Wolfart and Roeper, 2002). At $5 \mu \mathrm{M}$, mibefadil had no observable effect of the rhythmic firing of GP neurons $(p>$ 0.05 ; Kruskal-Wallis ANOVA; $n=6$; data not shown). This conclusion is consistent not only with our previous results but with those of others charting the distribution of Cav3 mRNA (Talley et al., 1999). Our conclusion is at odds with a previous study by Cooper and Stanford (2000) suggesting that Cav3 channels are expressed by principal GP neurons; however, this inference was based not on the actions of mibefadil but of $\mathrm{Ni}^{2+}$ at $1 \mathrm{mM}$, a concentration that is not selective for Cav3 channels (Todorovic and Lingle, 1998; Perez-Reyes 2003).

\section{$\mathrm{HCN}$ channels control the rate and regularity of autonomous pacemaking}

As noted above, a universal characteristic of GABAergic GP neurons was the presence of a sag in membrane voltage with hyperpolarizing current steps and a rebound discharge on cessation of current injection (Fig. 3A). This sag is the hallmark of HCN channels. To determine whether HCN channels contributed to the pacemaking mechanism, the relatively selective $\mathrm{HCN}$ channel antagonist ZD7288 (50 $\mu \mathrm{M})$ was applied (BoSmith et al., 1993; Harris and Constanti, 1995; Neuhoff et al., 2002). In every neuron sampled $(n=5)$, blockade of HCN channels produced a modest hyperpolarization and a reduction in firing rate and regularity. Recordings from a typical neuron are shown in Figure $3 B$ before and after the application of ZD7288. In our sample, ZD7288 decreased the median firing rate from 14.4 to $10.1 \mathrm{~Hz}$ $(p<0.05$; Kruskal-Wallis ANOVA; $n=8)$. To ensure that the inferred involvement of $\mathrm{HCN}$ channels in pacemaking was not an artifact of whole-cell recording, somatic cell-attached patch recordings were performed. In this recording mode, neurons spiked in much the same way as seen in whole-cell recordings. Bath application of ZD7288 $(50 \mu \mathrm{M})$ consistently led to a decrease in the rate and regularity of firing (Fig. $3 C)(n=8)$. The impact of $\mathrm{HCN}$ channel blockade on spike patterning also can be seen in autocorrelograms computed from representative trains (Fig. 3C, right). It is also important to note that the drop in spike rate produced by reduction in $\mathrm{HCN}$ channel currents was not limited to neurons that were firing at low rates; it occurred over a relatively wide range of spontaneous rates (Fig. 3D). To quantify the change in discharge regularity, the interspike interval (ISI) CV was calculated. Blockade of HCN channels increased the median interspike interval CV by a factor $>3$ (from 0.2 to $0.7 ; p<0.001$; Kruskal-Wallis ANOVA; $n=8$ ). A particularly prominent example is shown in Figure $3 E$, where the ISI distribution after drug application becomes positively skewed. An increased positive skew in the ISI histograms after HCN channel blockade was typical of our sample (8 of 8). The effect of ZD7288 on spike frequency and interval $\mathrm{CV}$ is summarized in a box plot format in Figure $3 F$. Similar results (Fig. $3 F$ ) were obtained with another
A

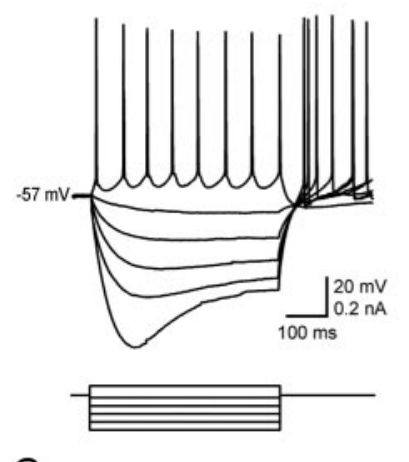

C

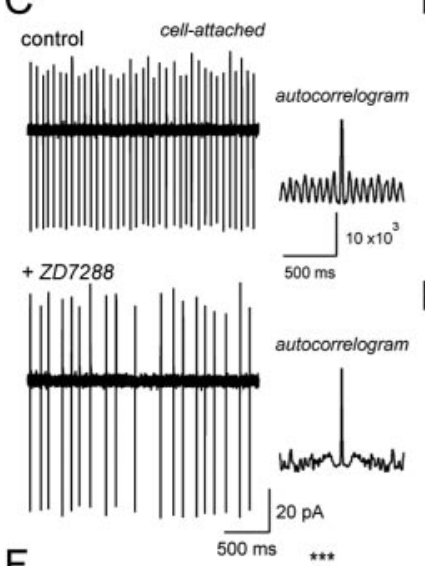

$\mathrm{F}$

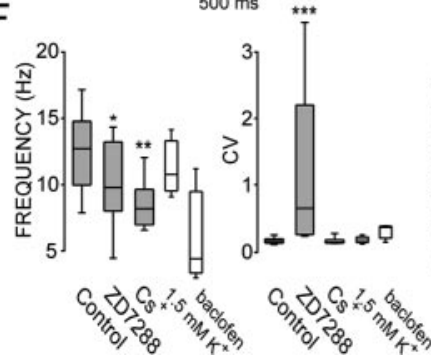

B control

whole-cell

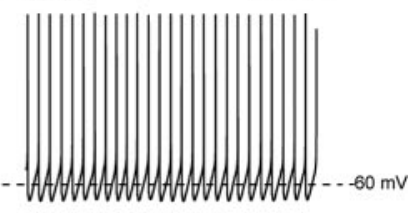

$+Z D 7288$

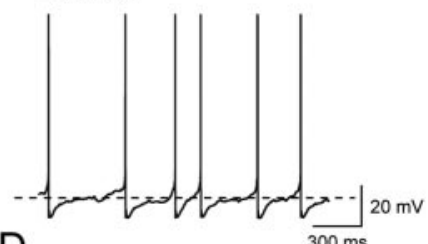

D

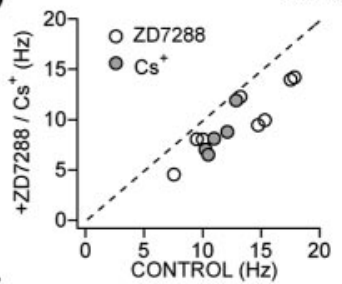

E
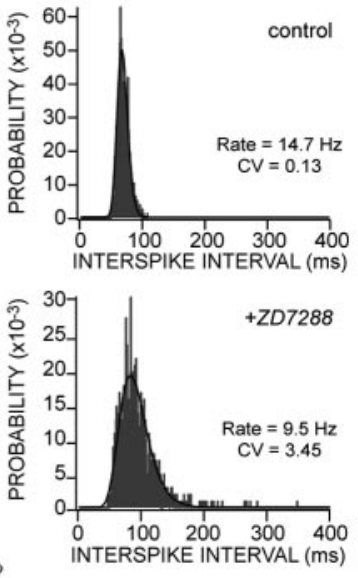

Figure 3. The rate and regularity of pacemaking in GP neurons is dependent on HCN channels. $A$, The response of a typical GP neuron to a series of current steps. These neurons discharged with little or no accommodation and exhibit prominent voltage-sag after hyperpolarizing current injection. $B$, Blockade of HCN channels with ZD7288 (50 $\mu \mathrm{m})$ produced a modest hyperpolarization, slowed spiking, and made it irregular. $C$, Somatic cell-attached ( $V_{\text {pipette }}=0$ $\mathrm{mV}$ ) recording (left panel) from a GP neuron in the absence and presence of $50 \mu \mathrm{m}$ ZD7288. Note the similarity of the change in spiking to that seen in whole-cell recording. Block of HCN channels with ZD7288 caused a marked reduction in the regularity of firing, as shown by the absence of clear peaks in the autocorrelogram (right panel). D, Plot of the discharge rate before (abscissa) and after application of HCN blockers (ZD72588, $\mathrm{Cs}^{+}$) in a sample of cells; the straight line has a slope of 1. E, Interspike interval histograms of the cell in C. Application of ZD7288 increased the modal interval and the interval variance. Black lines represent the best fit with a log normal distribution (control, 0.05; ZD7288, 0.02), peak (control, 65.2 msec; ZD7288, 79.7 $\mathrm{msec}$ ), and width (control, $17.4 \mathrm{msec} ; \mathrm{ZD} 7288,36.3 \mathrm{msec}$ ). F, Box plot summary of the change in discharge rate (left panel) and CV (right panel) after the application of ZD 72588 and Cs ${ }^{+}$or alterations in $\mathrm{K}^{+}$reversal potential or activation of a $\mathrm{K}^{+}$conductance (control, 14.4; ZD7288 $=10.1 \mathrm{~Hz} ; p<0.05$; Kruskal-Wallis ANOVA; $n=8$ ) and reflected more clearly by an increase CV of the interspike intervals (control, 0.2; ZD7288, 0.7; $p<0.001$; Kruskal-Wallis ANOVA; $n=8)$. Perfusion of $0.5 \mathrm{~mm} \mathrm{Cs}^{+}$, low external $\mathrm{K}^{+}(1.5 \mathrm{~mm})$, or baclofen $(10 \mu \mathrm{m})$ reduces firing frequency without significantly altering the regularity of firing.

HCN channel blocker, $\mathrm{Cs}^{+}(0.5 \mathrm{~mm} ; p<0.001$; Kruskal-Wallis ANOVA; $n=5$ ).

The decline in discharge regularity produced by HCN block cannot be explained simply by membrane hyperpolarization, be- 
cause lowering extracellular $\mathrm{K}^{+}$or activation of Kir3 channels with bath application of baclofen $(10 \mu \mathrm{M})$ failed to mimic the effects of ZD7288. In both cases, discharge rate slowed but remained highly regular (Fig. $3 F$ ).

\section{GABAergic GP neurons express HCN2 and HCN1 mRNA and protein}

HCN channels are multimeric transmembrane proteins constructed from a family of at least four subunits (HCN1-4) (Ludwig et al., 1998; Santoro et al., 1998; Franz et al., 2000; Monteggia et al., 2000; Santoro et al., 2000; Moosmang et al., 2001; Altomare et al., 2003; Ludwig et al., 2003). The subunit composition of $\mathrm{HCN}$ channels affects gating kinetics and sensitivity to cyclic nucleotides, making them important determinants of the functional role that the channels play. To determine the composition of HCN channels in GP neurons, RT-PCR and immunohistochemical approaches were used. First, serial dilution RT-PCR experiments were performed to determine the relative level of $\mathrm{HCN}$ subunit mRNA in GP tissue homogenates. In agreement with previous in situ hybridization studies (Santoro et al., 2000; Moosmang et al., 2001), these experiments found nominally high levels of HCN2 mRNA in the GP (Fig. 4A); however, both HCN1 and HCN3 mRNA also were readily detectable. Because the cellular makeup of the GP is not uniform, single-cell RT-PCR experiments were performed to determine $\mathrm{HCN}$ expression within identified GABAergic GP neurons. At this level, HCN2 mRNA was detected in all of the GAD67-expressing neurons, regardless of whether they coexpressed PV or ENK $(n=12)$ (Fig. $4 B$ ). As suggested by the tissue level analysis, $\mathrm{HCN} 1$ and to a lesser extent HCN3 mRNA were also detected in GAD67-expressing GP neurons; more than half ( 7 of 12 ) of the sample expressed detectable levels of HCN1 mRNA. Expression was not obviously related to PV or ENK expression, suggesting that the lower level of detection was attributable to a lower abundance of the HCN1 mRNA than of HCN2 mRNA.

Next, the regional and cellular distributions of HCN2 and $\mathrm{HCN} 1$ protein were examined using immunohistochemical approaches. As expected, HCN2 immunoreactivity was readily detected in the GP (Fig. 4C). Intense HCN2 immunoreactivity was found in the GP, entopeduncular nucleus, and thalamus. At higher magnification (Fig. 4C, right), a plexus of HCN2 immunoreactive neuropil can be seen in the GP. The distribution of $\mathrm{HCN} 1$ protein was investigated with two polyclonal antibodies directed against different, nonoverlapping intracellular epitopes (see Materials and Methods). The regional and cellular distribution of HCN1 immunostaining revealed with the two antibodies was virtually identical. As predicted from our previous study and other work (Santoro et al., 2000; Moosmang et al., 2001; Lorincz et al., 2002; Notomi and Shigemoto, 2004), the neocortex was heavily labeled (Fig. 4D). In agreement with the RT-PCR analysis, HCN1 immunoreactivity was also found within the GP, although it was decidedly less intense than that for the HCN2 subunit. A level of staining similar to that in the GP was found in the entopeduncular nucleus and thalamus. At higher magnification, HCN1 immunoreactivity in the GP (Fig. $4 D$, right) appeared to be exclusively in the neuropil.

HCN channel currents have gating properties consistent with coexpression of $\mathrm{HCN} 2$ and $\mathrm{HCN} 1$ subunits

The coexpression of HCN2 and HCN1 subunits suggests that HCN channel currents in GP neurons should have both fast and slow components (Ludwig et al., 1998; Santoro et al., 1998; Chen et al., 2001). To test this hypothesis, somatic whole-cell voltage-
A

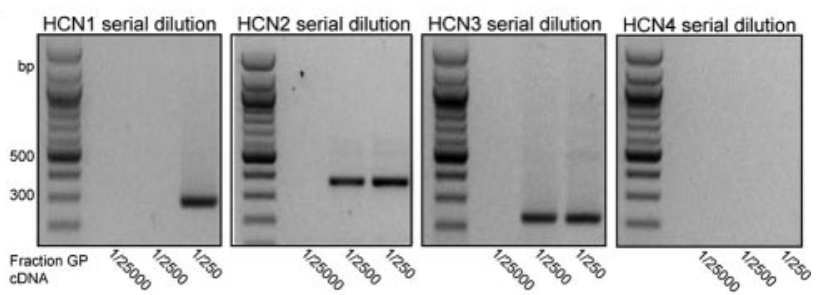

B
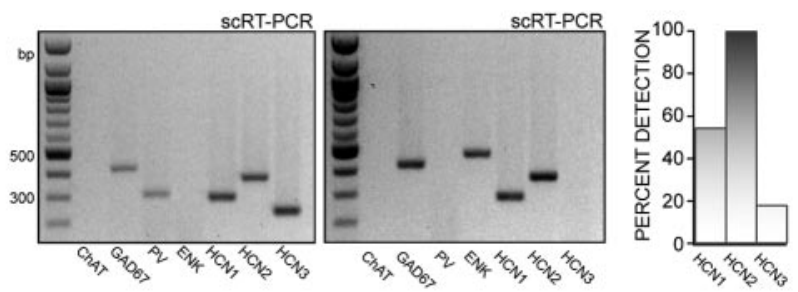

C

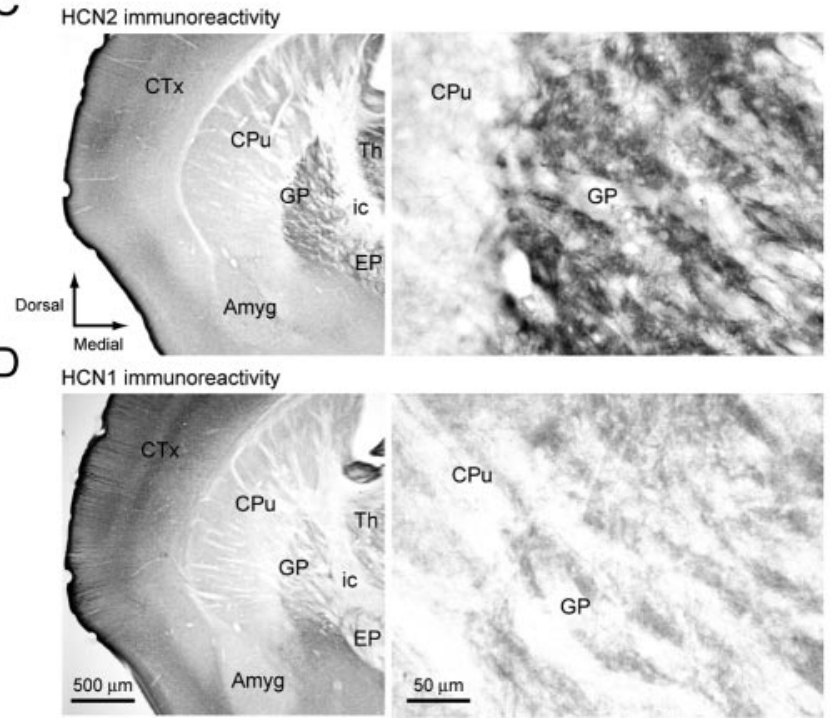

Figure 4. GABAergic GP neurons express primarily $\mathrm{HCN} 2$ and $\mathrm{HCN} 1$ subunits. $A$, Semiquantitative tissue level serial dilution RT-PCR analysis of HCN1-4 mRNA expression was performed to study the molecular determinants of HCN current. HCN2 and HCN3 mRNAs were expressed abundantly in GP. HCN1 mRNA was also readily detectable. In contrast, HCN4 mRNA was not detected. Therefore, subsequent sCRT-PCR profiling focused on HCN1-3 mRNAs. B, HCN1 and $\mathrm{HCN} 2$ are readily detected in the two principal populations of GABAergic GP neurons (PV+ and Enk +). C, Light micrographs showing HCN2 (top left) and HCN1 (bottom left) immunoreactivity patterns in two adjacent coronal sections. Dense HCN2 immunoreactivity was found in the GP, entopeduclar nucleus (EP), and thalamus (Th). Weak immunoreactivity for HCN2 was found in the striatum (CPu). Bundles of apical dendrites of neocortical pyramidal neurons were strongly immunopositive for HCN1. Weak to moderate neuropil labeling was found in the GP, EP, and Th. At higher magnification, dense $\mathrm{HCN} 2$ labeling was commonly found in the neuropil (top right). HCN1 immunoreactivity (top right) is exclusively in the neuropil in GP.

clamp recordings were made from GP neurons in the presence of $\mathrm{Ba}^{2+}(1 \mathrm{mM})$ to block inwardly rectifying Kir1-3 channels and of TTX $(1 \mu \mathrm{M})$ to block $\mathrm{Na}^{+}$channels and synaptic activity. HCN channels were activated with hyperpolarizing voltage steps of varying amplitude from a holding potential of $-50 \mathrm{mV}$ (Fig. 5A). To generate a relative conductance estimate, the first step was followed by a second step to $-130 \mathrm{mV}$ to maximally activate channels (DiFrancesco, 1986; Maccaferri et al., 1993; Maccaferri and McBain, 1996; Franz et al., 2000). Examination of the currents evoked by hyperpolarization on semi-log plots revealed that they were clearly bi-exponential, with fast and slow exponential components (Fig. 5A, right), with time constants in the range 
A

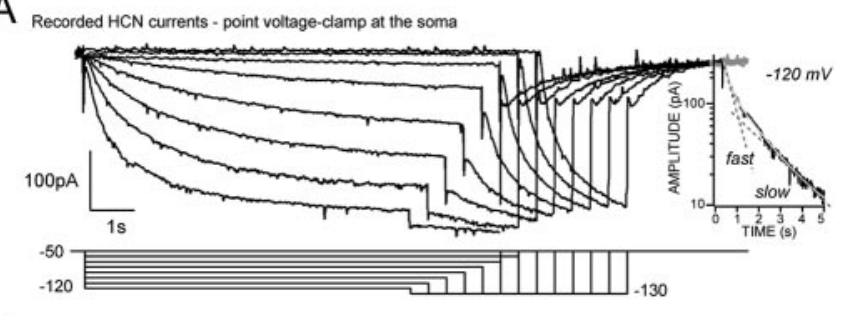

B

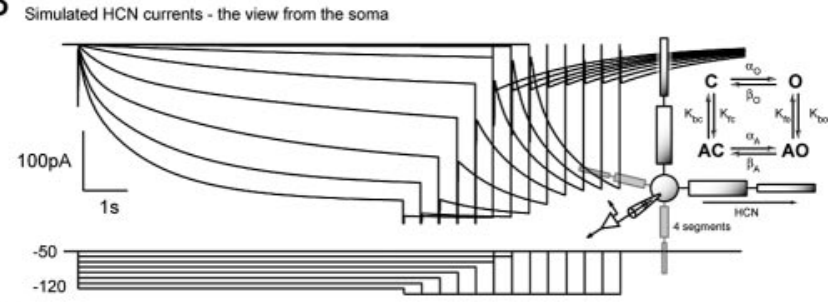

C

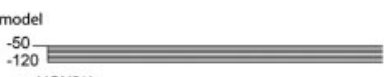

$\mathrm{HCN} 2 / 1$

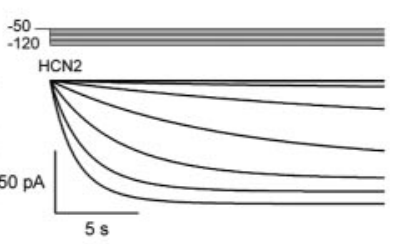

D

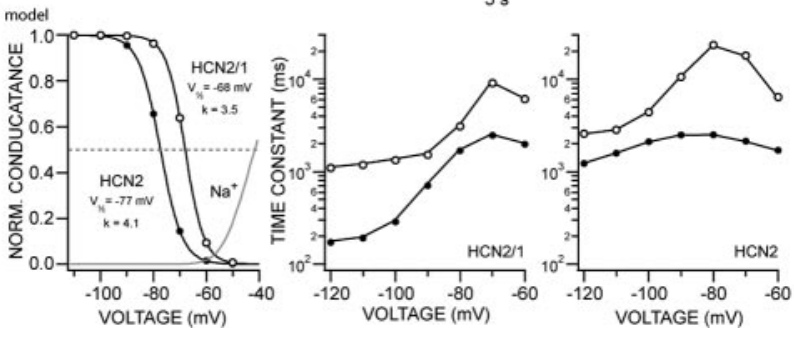

Figure 5. HCN currents in GP neurons can be simulated with dendritic placement of HCN2 and HCN2/1 channels. $A, \mathrm{HCN}$ current elicited by a series of voltage steps in a GP neuron. The activation of the HCN current is bi-exponential (right). $B$, Simulation of HCN currents with a four-state allosteric model. C, Simulated currents evoked by voltage steps in HCN2/1 and HCN2 channels. Note the differences in kinetics of the two channel types. D, Summary of steady-state voltage dependence and gating kinetics in the two canonical channel models. These models were adapted from Chen et al. (2001) and Wang et al. (2002) for the simulation in B. Also shown in $D$ is the foot of the experimentally determined $\mathrm{Na}^{+}$channel activation plot (gray line).

expected of HCN2- and HCN1-containing channels (Chen et al., 2001; Wang et al., 2002).

The problem with the interpretation of these experiments is that GP neurons have dendrites, and the transmembrane voltage in dendritic regions, where $\mathrm{HCN}$ channel density is highest, is unlikely to be adequately controlled despite the pharmacological isolation of HCN channels in these regions. In essence, our recordings yield somatic "point-clamp" measurements. The most straightforward way to deal with this problem is to make dendritic patch recordings (Magee, 1998); however, this proved difficult because of the caliber of the dendrites and the fiber content of the GP. As an alternative, computer simulations were performed using the program NEURON (Hines and Carnevale, 1997). With an anatomically simplified representation of a GP neuron possessing four equivalent primary dendrites extending from a spherical soma, the Multi-Run Fitter in NEURON was used to estimate the distribution of $\mathrm{HCN}$ channels required to reproduce the somatic point-clamp data shown in Figure $5 \mathrm{~A}$. NEURON was given two channels to work with that were based on the allosteric model of HCN gating advanced by Siegelbaum and colleagues (Chen et al., 2001; Wang et al., 2002): one had gating properties like HCN2 homomeric channels, and the other had gating properties like $\mathrm{HCN} 2 / \mathrm{HCN} 1$ heteromeric channels when expressed in heterologous systems. Cyclic nucleotide concentrations were assumed to be low $(10 \mathrm{nM})$. With these constraints, NEURON was able to accurately reproduce the experimental data with a modest adjustment of the channel gating parameters and an $\mathrm{HCN} 2$ to $\mathrm{HCN} 2 / 1$ ratio of 2.5 in proximal and distal dendritic compartments (Fig. $5 B$ ). The contribution of each channel type to the aggregate somatic currents is shown in Figure $5 C$. The steady-state voltage dependence and activation kinetics of each channel type were measured and plotted (Fig. $5 D$ ). Both aspects of channel gating were surprisingly close to those reported previously (Chen et al., 2001; Wang et al., 2002) and make the case that HCN channels in GP neurons have properties that help support pacemaking. To illustrate this point, the foot of the $\mathrm{Na}^{+}$channel activation plot is shown in Figure $5 \mathrm{D}$ (gray line), where it can be seen to significantly overlap the HCN activation curves, particularly that of the HCN2/HCN1 channel. This is precisely the condition needed to support pacemaking.

\section{HCN channels sculpt the response to striatal GABAergic input and promote pacemaker resetting}

GP projection neurons receive a rich GABAergic synaptic input from the striatum that primarily targets their dendrites (Gerfen and Wilson, 1996; Smith et al., 1998). Alterations in the striatal GABAergic input to GP neurons may trigger the emergence of synchronous burst firing within the GP-STN network that is characteristic of PD models (Terman et al., 2002). HCN channels in GP neurons are perfectly positioned to sculpt this inhibitory input and potentially influence the way in which it alters pacemaking.

To test this possibility, striatal GABAergic inputs to GP were activated during whole-cell recording of GP neurons in a tissue slice (Fig. $6 B$ ). Striatal stimulation (two brief pulses separated by $50 \mathrm{msec})$ consistently caused GP neurons to pause (Fig. 6A) $(n=$ $5)$. Not only did the striatal input cause GP neurons to pause, it very precisely reset the pacemaking mechanism. The resetting can be seen by overlaying traces from successive trials and aligning the traces on the striatal stimulation (which was asynchronously delivered). Compilation of peristimulus time histograms (PSTHs) (Fig. 6D) shows the same clear resetting with striatal stimulation. This resetting is similar to that observed by Stanford (2003) after local stimulation within the GP, suggesting that it was caused by striatal fibers. Because ZD7288 appeared to affect presynaptic release (Chevaleyre and Castillo, 2002), $\mathrm{Cs}^{+}$was used to manipulate $\mathrm{HCN}$ channels. Partial blockade of $\mathrm{HCN}$ channels with $\mathrm{Cs}^{+}(0.5 \mathrm{~mm})$ did not eliminate the pause; in fact it became longer in duration (Fig. $6 \mathrm{~A})\left(+\mathrm{Cs}^{+}\right)$, but the resetting of the pacemaking mechanism was lost, as is evident in the trace overlay (Fig. 6C) and in the PSTH (Fig. 6D). Overlaying traces generated before and after $\mathrm{Cs}^{+}$application revealed that it was the membrane potential trajectory after the delivery of the striatal stimuli that was clearly changed (Fig. 6C). With functional HCN channels, the membrane potential returned to spike threshold more rapidly and in a very stereotyped manner. The declining ability of striatal stimulation to reset pacemaking with progressive HCN channel block also is illustrated in a raster plot (Fig. $6 E$ ). In line with the dendritic localization of the HCN channels, intrasomatic injection of hyperpolarizing current steps was not nearly as effective in resetting the pacemaking mechanism as synaptic stimulation (Fig. $6 A, D$, bottom) $(n=12)$. The ability of striatal stimulation to reset the pacemaking mechanism and its dependence on HCN channels was not an artifact of whole-cell 
recording, because it was readily seen in cell-attached recordings (Fig. $6 F)(n=5)$.

These results argue that dendritic $\mathrm{HCN}$ channels in GP neurons are activated by transient striatal GABAergic input and that their activation truncates the striatal IPSP and resets the pacemaking mechanism. Although this interpretation is consistent with previous studies showing that HCN-like channels can shorten $\mathrm{GABA}_{\mathrm{A}}$ receptor-mediated IPSPs (Williams and Stuart, 2003), the ability of brief striatal stimulation to engage HCN channels in GP neurons is somewhat surprising given the dominance of kinetically slow HCN2 channels. HCN2 channels should respond to sustained, but not transient, hyperpolarization. To help clarify the mechanism underlying the striatal resetting, the ability of IPSP waveforms to activate HCN2 and HCN2/1 channels was examined using a NEURON simulation. The simulation was run in an isopotential sphere with HCN2 and HCN2/1 channels having properties and densities estimated from the experimental data (Fig. 5). Delivery of IPSP voltage waveforms intended to roughly mimic the striatal IPSP $(\tau=25 \mathrm{msec}$ ) (Fig. $7 \mathrm{~A}$, blue lines) effectively activated HCN2/1 heteromeric channels but was much less efficient at activating HCN2 channels (Fig. $7 B$ ). It also was evident that at the holding potential of $-60 \mathrm{mV}, \mathrm{HCN} 2 / 1$ channels provided a much larger resting conductance than HCN2 channels because of the differences in their steady-state activation properties. As the duration of the IPSP waveform was increased $(\tau=100 ; 500$ $\mathrm{msec})$, there was a progressively stronger activation of both HCN2 and HCN2/1 channels, but heteromeric channels remained the most efficiently activated because the $20 \mathrm{mV}$ IPSP traversed the steepest part of the activation curve of these channels (Fig. 5D). With larger (nonphysiological) IPSP amplitudes, the activation of $\mathrm{HCN} 2$ channels matched that of HCN2/1 channels (data not shown).

These simulations suggest that HCN2/1 channels were critical to pacemaker resetting by brief striatal stimulation. To provide a more direct test of this hypothesis, a model of GP pacemaking was constructed in NEURON. Using biophysically accurate models of voltage-dependent $\mathrm{Na}^{+}$and $\mathrm{K}^{+}$channels found in GP neurons, the multicompartment model mimicked the voltage trajectories and autonomous pacemaking of GP neurons (see Materials and Methods). Membrane voltage noise was added to the model to increase discharge variability into a range seen experimentally. Delivery of a brief IPSP pair to one of the dendrites effectively reset the pacemaking of the model (Fig. 7D, top), much as observed experimentally (compare Fig. $6 \mathrm{~A}$ ). If the density of $\mathrm{HCN} 2 / 1$ channels was reduced to $25 \%$ of the control density, pacemaking was modestly slowed, and the ability of the IPSPs to reset the pacemaking was disrupted (Fig. $7 D$, second panel) despite the fact that the pause was
B

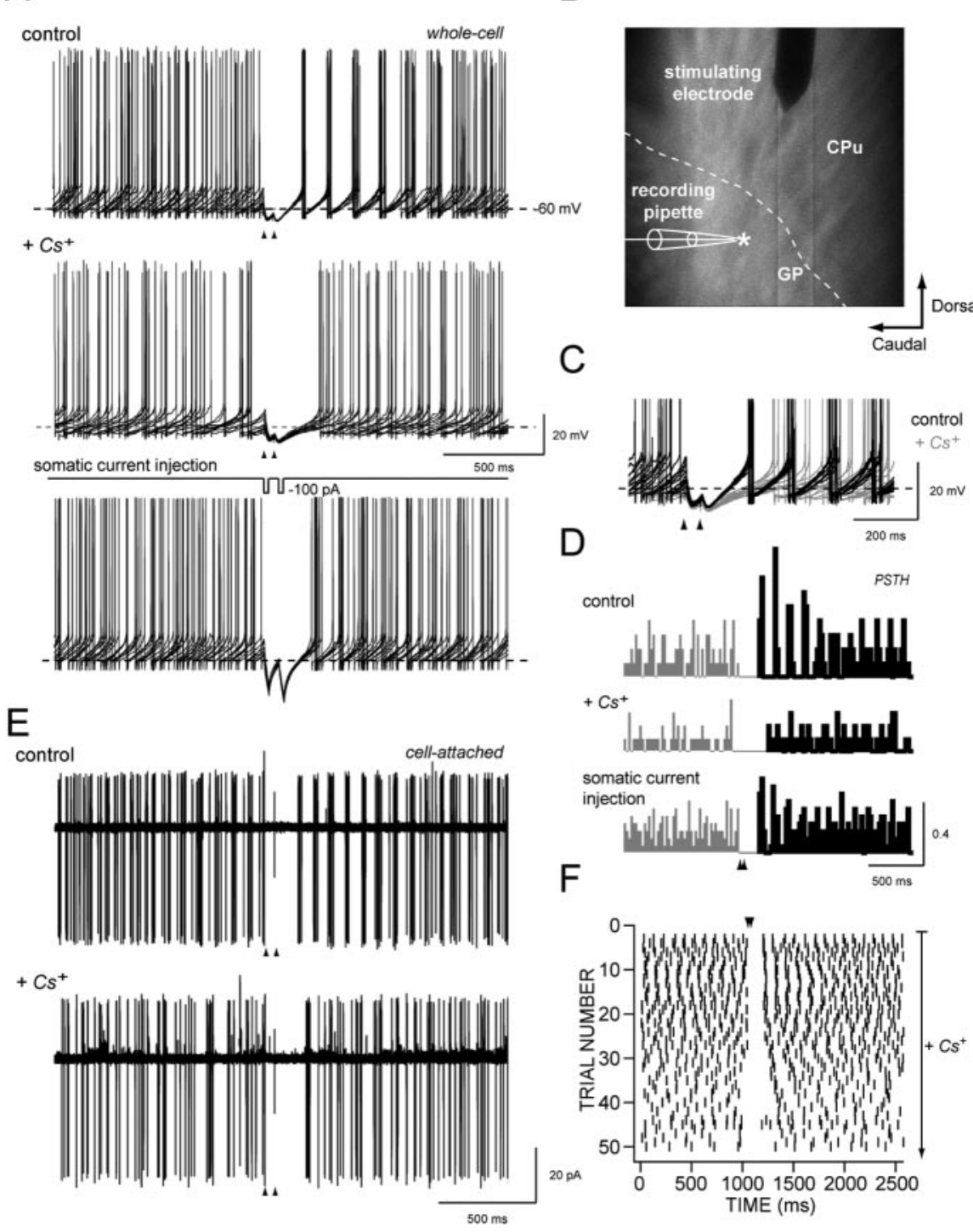

Figure 6. HCN channel currents sculpt striatal GABAergic input to GP neurons and enable resetting. A, Top, Whole-cell recordings from a GP neuron after striatal stimulation with two pulses (arrowheads) delivered at $20 \mathrm{~Hz}$. Traces are aligned on the striatal stimulation. The stimulation induced a pause and the resetting of the pacemaking. Middle, The resetting of spiking was reversibly of stimulating and recording electrodes. C, Overlay of traces before and after $\mathrm{Cs}^{+}(A)$, showing how $\mathrm{Cs}^{+}$eliminated the stereostimulation. $E$, A raster plot of spiking before and during the application of $\mathrm{Cs}^{+}(0.5 \mathrm{~mm})$. The intertrial interval was $20 \mathrm{sec} . F$, Cell-attached recording of a typical GP neuron showing the similarity of the effect of $\mathrm{Cs}^{+}$to that seen with whole-cell recording.

lengthened. This behavior resembled that observed experimentally after $\mathrm{HCN}$ block with $\mathrm{Cs}^{+}$. Further reduction of $\mathrm{HCN} 2 / 1$ channel density ( $5 \%$ of control) eliminated all signs of resetting (Fig. $7 D$, third panel). To determine whether channel density alone was the issue, HCN2/1 heteromeric channels were replaced with HCN2 channels, maintaining the total HCN channel density (Fig. $7 D$, fourth trace). In this case, the ability of dendritic IPSPs to reset the pacemaking mechanism was lost, despite the fact that the IPSP itself and the pause in discharge were longer than that seen with reduced HCN channel density. Finally, IPSPs delivered to the soma produced modest resetting, mimicking experimental results with somatic current injection (Fig. 7D, bottom). The impact of HCN2/1 and HCN2 channels on the first spike latency and variability is summarized in Figure $7 E$. These simulations not only confirm the involvement of 
A

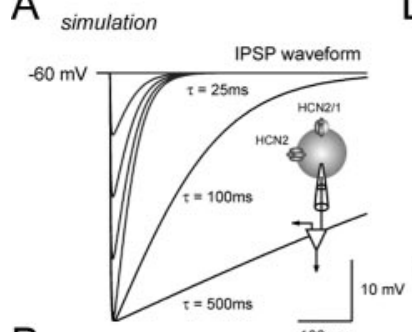

B

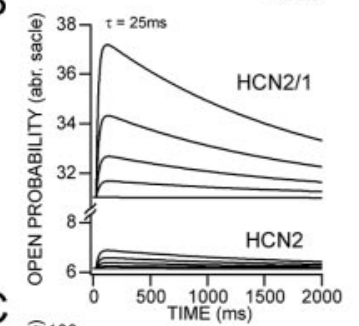

$\mathrm{C}$

E
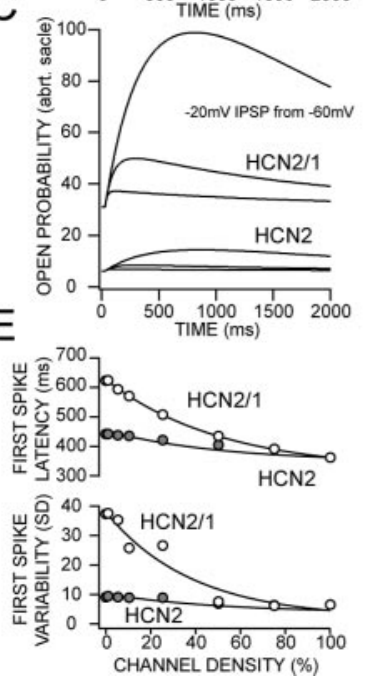

simulation
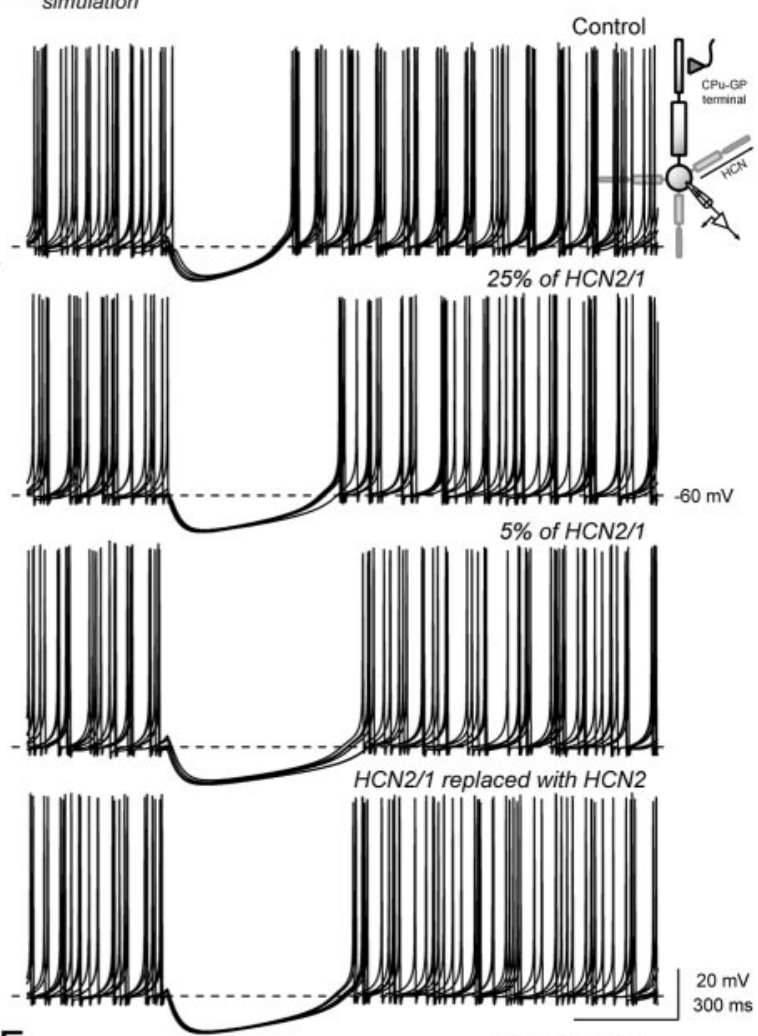

$\mathrm{F}$

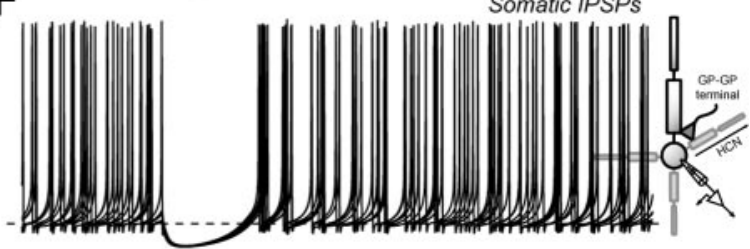

Figure 7. Simulations suggest that $\mathrm{HCN} 2 / 1$ heteromeric channels are crucial for resetting by striatal IPSPs. A, A family of IPSP waveforms with varying amplitude and kinetics was used in the simulations. B, A brief IPSP waveform ( $25 \mathrm{msec}$ time constant; see A) delivered from a holding potential of $-60 \mathrm{mV}$ activated $\mathrm{HCN} 2 / 1$ channels efficiently over a wide range of amplitudes but did not activate $\mathrm{HCN} 2$ channels efficiently. The simulation was run with an isopotential sphere having both channel types inserted. $C$, Keeping the amplitude of the IPSP constant and varying the time constant led to significant activation of HCN2 channels only with the slowest (red; $\tau=500 \mathrm{msec}$ ) IPSP. In both $B$ and $C$, open probability is plotted rather than current. The differences in HCN2/1 and HCN2 channel activation by the waveform reflect the differences in kinetics and voltage dependence (Fig. 5). D, A model of GP pacemaking was constructed that reproduced many of the features of the experimentally observed spiking. In the model, a pair of dendritic IPSPs reset pacemaking as shown at the top, where traces from the simulation are aligned at the simulated IPSP pair. In the next set of traces, the HCN2/1 density is reduced to $25 \%$ of the control level. Note the disruption of resetting. Next, the HCN2/1 channel density was reduced to $5 \%$ of the control. Note that pacemaking is not reset. Next, the HCN density was restored to the control level, but HCN2/1 channels were replaced with HCN2 channels. Note that resetting is again disrupted. Last, somatic IPSPs producing a hyperpolarization like that seen at the top failed to reset pacemaking efficiently in a control simulation. Increasing the amplitude of the somatic IPSP to recruit dendritic HCN channels did begin to reset pacemaking but only with very large IPSPS. $E$, Plot of first spike latency (top) and the SD of first spike latency in simulations (measured from the onset of the IPSPs) (bottom) during which HCN2 channel density was held constant and HCN2/1 channel density was progressively decreased $(O)$ or where HCN2/1 density was held constant and HCN2 channel density was progressively decreased (O). Note that reducing HCN2/1 channel density altered first spike latency and its variability significantly, whereas altering HCN2 density had little effect.

dendritic $\mathrm{HCN}$ channels in the mechanism by which striatal IPSPs reset pacemaking in GP neurons, they argue that the expression of a relatively small complement of HCN1 subunits and the formation of HCN2/1 heteromeric channels is critical to this mechanism.

\section{Discussion}

GABAergic GP projection neurons are autonomous pacemakers

In vivo, the principal neurons of the rodent GP, as well as those of the homologous primate GPe, have high "resting" discharge rates
(DeLong, 1971; Bergstrom and Walters, 1981). It has long been assumed that this activity was driven by excitatory synaptic input from the STN (Kitai and Kita, 1987; Parent and Hazrati, 1995). The work described here shows that excitatory input is not necessary to maintain activity. In particular, we show that the principal neurons of the GP-GABAergic projection neurons that express PV or ENK (Kita, 1994; Rajakumar et al., 1994; Hontanilla et al., 1998; Hoover and Marshall, 1999; Voorn et al., 1999; Kita and Kita, 2001)_ are highly regular, autonomous pacemakers. In tissue slices, the discharge rate and its regularity were unaffected by blockade of glutamatergic or GABAergic synaptic receptors, demonstrating the autonomy of the discharge. This finding is consistent with previous studies showing a subset of neurons with pacemaking properties within the confines of the GP (Nambu and Llinas, 1994, 1997; Cooper and Stanford, 2000). Pacemaking in these neurons is dependent on voltage-dependent $\mathrm{Na}^{+}$channels, as demonstrated by the ability of TTX to eliminate spiking and membrane potential oscillations (Nambu and Llinas, 1994; Stanford, 2003). Although $\mathrm{Na}^{+}$ channel-dependent pacemaking is found in a number of central neurons (Raman and Bean, 1999; Bennett et al., 2000; Taddese and Bean, 2002), it is by no means universal (Yung et al., 1991; Huguenard, 1996; McCormick and Bal, 1997; Wolfart and Roeper, 2002).

The fact that GABAergic GP neurons are autonomous pacemakers does not exclude an important role for extrinsic synaptic connections in determining the discharge rate in vivo. In unanesthetized, intact preparations, the discharge of GPe neurons is often considerably greater than that seen here, a difference that is likely to be attributable to the maintenance of excitatory STN inputs in vivo (Bevan et al., 2002). The highly regular autonomous discharge of GP neurons may act as a carrier for motor command signals arising out of the interplay between this STN input and the GABAergic, inhibitory input arising from the striatum.

The rate and regularity of pacemaking in GP neurons depends on HCN channels

Despite the fact that pacemaking in GP principal neurons depend on voltage-dependent $\mathrm{Na}^{+}$channel currents, these currents are not sufficient to explain the properties of GP pacemaking. HCN channels appear to partner with $\mathrm{Na}^{+}$channels in this process, as in various other pacemakers (Pape, 1996; Clapham, 1998; Luthi and McCormick, 1998; Santoro and Tibbs, 1999; Accili et al., 2002; Robinson and Siegelbaum, 2003). The most compelling evidence for this conclusion comes from the observation that 
blockade of HCN channels with either ZD7288 or low concentrations of $\mathrm{Cs}^{+}$(BoSmith et al., 1993; Harris and Constanti, 1995; Pape, 1996; Neuhoff et al., 2002) had profound effects on pacemaking. HCN channels serve this function by delivering an inward depolarizing current at negative membrane potentials. In GP neurons, HCN channels began to activate around $-55 \mathrm{mV}$, near the foot of the $\mathrm{Na}^{+}$channel activation curve. This helps to ensure that the membrane potential does not stabilize at membrane potentials below those needed to activate $\mathrm{Na}^{+}$channels and the next spike cycle. Because of the relatively slow kinetics of $\mathrm{HCN}$ channel deactivation, this depolarizing influence is felt throughout the pacemaking cycle, increasing during the postspike afterhyperpolarization (as driving force increases).

\section{GP projection neurons express $\mathrm{HCN} 2$ and $\mathrm{HCN} 1$ subunits and kinetically heterogeneous currents}

The gating properties of $\mathrm{HCN}$ channels and their functional role are dependent on subunit composition (Ludwig et al., 1998; Santoro et al., 1998; Franz et al., 2000; Monteggia et al., 2000; Santoro et al., 2000; Moosmang et al., 2001; Altomare et al., 2003; Ludwig et al., 2003). HCN channels in GABAergic GP projection neurons appear to be constructed from HCN2 and HCN1 subunits, with HCN2 being the dominant subunit. This conclusion is based on scRT-PCR profiling showing coexpression of HCN2 and HCN1 subunit mRNA in GABAergic projection neurons and on immunohistochemical analysis. Our results differ from previous work (Santoro et al., 1998; Moosmang et al., 2001) only in the resolution of a modest HCN1 expression in the GP.

Although HCN1 subunit mRNA and protein in projection neurons were relatively low, the admixture helps to explain the electrophysiological properties of HCN currents in GP neurons. Hyperpolarizing somatic voltage steps evoked currents that were blocked by ZD7288 and micromolar concentrations of Cs ${ }^{+}$, pharmacological hallmarks of HCN channels (BoSmith et al., 1993; Harris and Constanti, 1995; Pape, 1996; Neuhoff et al., 2002). These currents had both fast and slow components, as expected of a mixture of HCN1 and HCN2 channels (Chen et al., 2001; Wang et al., 2002). Computer simulations were performed to determine whether this feature of the currents could simply be a space-clamp artifact attributable to the dendritic placement of HCN channels. These simulations used a simplified but experimentally anchored model of the GP dendritic tree (Iwahori and Mizuno, 1981; Park et al., 1982; Millhouse, 1986). The model also used descriptions of HCN channel gating generated from preparations in which the subunit composition of the channels was known and there were no space-clamp issues (Chen et al., 2001; Wang et al., 2002). Our studies suggested that the somatic pointclamp data generated could not be explained by the presence of a single, slow HCN2 channel. Inclusion of a second population of channels with faster kinetics and depolarized voltage dependence, like those described for $\mathrm{HCN} 1 / \mathrm{HCN} 2$ heteromeric channels, was critical to the simulation of somatic evoked currents and pacemaking.

\section{Striatal GABAergic synaptic input resets pacemaking}

$\mathrm{HCN}$ channels were not only important for pacemaking but were also important determinants of the response to striatal GABAergic synaptic input. GP projection neurons receive two prominent GABAergic synaptic inputs: one arising from striatopallidal neurons and another arising from recurrent collaterals of GP neurons (Kita, 1994; Nambu and Llinas, 1994; Bevan et al., 1998; Sato et al., 2000). The subcellular distribution of these GABAergic synaptic contacts are quite different: the recurrent collateral contacts are somatic, whereas the striatopallidal contacts are primarily dendritic.

Brief activation of the striatopallidal GABAergic input to GP neurons induced membrane hyperpolarization and a pause in pacemaking. This pause in spiking was similar in both whole-cell and cell-attached recordings, indicating that it was not an artifact of disruption of the chloride equilibrium potential. Not only did striatal stimulation pause spiking, it reset the pacemaking mechanism in GP neurons. Stanford (2003) found a similar response to local electrical stimulation. This phenomenon appeared to be dependent on dendritic localization of the synapses, because somatic injection of hyperpolarizing current pulses did not efficiently reset pacemaking. Partial block of dendritic HCN channels lengthened the pause in activity, as expected from previous work showing that these cationic channels are capable of abbreviating synaptically induced hyperpolarization (Williams and Stuart, 2003). More importantly perhaps, disruption of HCN channels essentially eliminated the temporal relationship between the striatal stimulation and the phase of pacemaking. Although it is possible that antidromic activation of pallidostriatal axons contributed to the effects of striatal stimulation (Kita and Kitai, 1991; Nambu and Llinas, 1994; Bevan et al., 1998), it is unlikely that this was a major factor because somatic current injection, which should mimic recurrent activation of pallidostriatal axons, failed to robustly induce resetting.

In an attempt to provide a better mechanistic understanding of this phenomenon, simulations were performed with a model that included key conductances known to regulate pacemaking in GP neurons (Baranauskas et al., 1999; Tkatch et al., 2000; Baranauskas et al., 2003). The model accurately reproduced the experimentally observed membrane potential trajectory of GP neurons and autonomous pacemaking in the $10-15 \mathrm{~Hz}$ range. Dendritic inhibitory synaptic stimulation of the model induced a pause in activity and reset pacemaking, as found experimentally. Moreover, reducing HCN channels in the dendrites lengthened the pause and disrupted the resetting behavior, just as $\mathrm{Cs}^{+} \mathrm{did}$ experimentally. Just as interesting, keeping total $\mathrm{HCN}$ channel density constant but replacing $\mathrm{HCN} 2 / 1$ heteromeric channels with HCN2 channels had much the same effect as reducing HCN density. This change is attributable to (1) the depolarized voltage dependence of the HCN2/1 channels that increases HCN channel participation during pacemaking and (2) the faster HCN channel kinetics afforded by inclusion of the HCN1 subunit, enabling opening by relatively brief GABAergic IPSPs.

\section{Implications for the mechanisms underlying GP synchrony in Parkinson's disease}

In PD, GP neurons and the tightly coupled neurons in the STN spike in synchronous rhythmic bursts. The motor symptoms of the disease are thought to arise from this pathological spiking pattern (Bergman et al., 1998; Vitek, 2002). The mechanisms responsible for the emergence of the synchronous discharge have yet to be clearly defined. Recent simulations of the GP/STN network argue that enhanced striatopallidal inhibition after striatal dopamine depletion could trigger the development of synchrony (Terman et al., 2002). Our data are strongly supportive of this model, providing clear evidence that striatopallidal GABAergic synaptic contacts are capable of resetting the pacemaking mechanism in GP projection neurons. In this way, shared striatopallidal input or simply temporally correlated activity should be capable of inducing phase synchrony among a subpopulation of GP neurons. Furthermore, our data suggest that this feature of the 
GP response to striatopallidal activity is dependent on dendritic HCN channels containing HCN1 subunits.

\section{References}

Accili EA, Proenza C, Baruscotti M, DiFrancesco D (2002) From funny current to HCN channels: 20 years of excitation. News Physiol Sci 17:32-37.

Altomare C, Terragni B, Brioschi C, Milanesi R, Pagliuca C, Viscomi C, Moroni A, Baruscotti M, DiFrancesco D (2003) Heteromeric HCN1-HCN4 channels: a comparison with native pacemaker channels from the rabbit sinoatrial node. J Physiol (Lond) 549:347-359.

Baranauskas G, Tkatch T, Surmeier DJ (1999) Delayed rectifier currents in rat globus pallidus neurons are attributable to Kv2.1 and Kv3.1/3.2 K(+) channels. J Neurosci 19:6394-6404.

Baranauskas G, Tkatch T, Nagata K, Yeh JZ, Surmeier DJ (2003) Kv3.4 subunits enhance the repolarizing efficiency of Kv3.1 channels in fast-spiking neurons. Nat Neurosci 6:258-266.

Bengtson CP, Osborne PB (2000) Electrophysiological properties of cholinergic and noncholinergic neurons in the ventral pallidal region of the nucleus basalis in rat brain slices. J Neurophysiol 83:2649-2660.

Bennett BD, Callaway JC, Wilson CJ (2000) Intrinsic membrane properties underlying spontaneous tonic firing in neostriatal cholinergic interneurons. J Neurosci 20:8493-8503.

Berger T, Larkum ME, Luscher HR (2001) High I(h) channel density in the distal apical dendrite of layer $\mathrm{V}$ pyramidal cells increases bidirectional attenuation of EPSPs. J Neurophysiol 85:855-868.

Bergman H, Feingold A, Nini A, Raz A, Slovin H, Abeles M, Vaadia E (1998) Physiological aspects of information processing in the basal ganglia of normal and parkinsonian primates. Trends Neurosci 21:32-38.

Bergstrom DA, Walters JR (1981) Neuronal responses of the globus pallidus to systemic administration of D-amphetamine: investigation of the involvement of dopamine, norepinephrine, and serotonin. J Neurosci $1: 292-299$.

Bevan MD, Booth PA, Eaton SA, Bolam JP (1998) Selective innervation of neostriatal interneurons by a subclass of neuron in the globus pallidus of the rat. J Neurosci 18:9438-9452.

Bevan MD, Magill PJ, Terman D, Bolam JP, Wilson CJ (2002) Move to the rhythm: oscillations in the subthalamic nucleus-external globus pallidus network. Trends Neurosci 25:525-531.

BoSmith RE, Briggs I, Sturgess NC (1993) Inhibitory actions of ZENECA ZD7288 on whole-cell hyperpolarization activated inward current (If) in guinea-pig dissociated sinoatrial node cells. Br J Pharmacol 110:343-349.

Chen S, Wang J, Siegelbaum SA (2001) Properties of hyperpolarizationactivated pacemaker current defined by coassembly of HCN1 and HCN2 subunits and basal modulation by cyclic nucleotide. J Gen Physiol 117:491-504.

Chevaleyre V, Castillo PE (2002) Assessing the role of Ih channels in synaptic transmission and mossy fiber LTP. Proc Natl Acad Sci USA 99:9538-9543.

Cimino GD, Metchette K, Isaacs ST, Zhu YS (1990) More false-positive problems. Nature 345:773-774.

Clapham DE (1998) Not so funny anymore: pacing channels are cloned. Neuron 21:5-7.

Cooper AJ, Stanford IM (2000) Electrophysiological and morphological characteristics of three subtypes of rat globus pallidus neurone in vitro. J Physiol (Lond) 527:291-304.

DeLong MR (1971) Activity of pallidal neurons during movement. J Neurophysiol 34:414-427.

DiFrancesco D (1986) Characterization of single pacemaker channels in cardiac sino-atrial node cells. Nature 324:470-473.

Filion M, Tremblay L (1991) Abnormal spontaneous activity of globus pallidus neurons in monkeys with MPTP-induced parkinsonism. Brain Res 547:142-151.

Filion M, Tremblay L, Bedard PJ (1991) Effects of dopamine agonists on the spontaneous activity of globus pallidus neurons in monkeys with MPTPinduced parkinsonism. Brain Res 547:152-161.

Franz O, Liss B, Neu A, Roeper J (2000) Single-cell mRNA expression of HCN1 correlates with a fast gating phenotype of hyperpolarizationactivated cyclic nucleotide-gated ion channels (Ih) in central neurons. Eur J Neurosci 12:2685-2693.

Gerfen C, Wilson C (1996) The basal ganglia. Heidelberg: Springer.

Hanson J, Smith Y, Jaeger D (2004) Sodium channels and dendritic spike initiation at excitatory synapses in globus pallidus neurons. J Neurosci 24:329-340.

Harris NC, Constanti A (1995) Mechanism of block by ZD 7288 of the hyperpolarization-activated inward rectifying current in guinea pig substantia nigra neurons in vitro. J Neurophysiol 74:2366-2378.

Hines ML, Carnevale NT (1997) The NEURON simulation environment. Neural Comput 9:1179-1209.

Holderith NB, Shigemoto R, Nusser Z (2003) Cell type-dependent expression of HCN1 in the main olfactory bulb. Eur J Neurosci 18:344-354.

Hontanilla B, Parent A, de las Heras S, Gimenez-Amaya JM (1998) Distribution of calbindin D-28k and parvalbumin neurons and fibers in the rat basal ganglia. Brain Res Bull 47:107-116.

Hoover BR, Marshall JF (1999) Population characteristics of preproenkephalin mRNA-containing neurons in the globus pallidus of the rat. Neurosci Lett 265:199-202.

Huguenard JR (1996) Low-threshold calcium currents in central nervous system neurons. Annu Rev Physiol 58:329-348.

Iwahori N, Mizuno N (1981) A Golgi study on the globus pallidus of the mouse. J Comp Neurol 197:29-43.

Kita H (1994) Parvalbumin-immunopositive neurons in rat globus pallidus: a light and electron microscopic study. Brain Res 657:31-41.

Kita H, Kitai ST (1987) Efferent projections of the subthalamic nucleus in the rat: light and electron microscopic analysis with the PHA-L method. J Comp Neurol 260:435-452.

Kita H, Kitai ST (1991) Intracellular study of rat globus pallidus neurons: membrane properties and responses to neostriatal, subthalamic and nigral stimulation. Brain Res 564:296-305.

Kita H, Kita T (2001) Number, origins, and chemical types of rat pallidostriatal projection neurons. J Comp Neurol 437:438-448.

Kitai S, Kita H (1987) Structure and function: current concepts. New York: Plenum.

Lorincz A, Notomi T, Tamas G, Shigemoto R, Nusser Z (2002) Polarized and compartment-dependent distribution of HCN1 in pyramidal cell dendrites. Nat Neurosci 5:1185-1193.

Ludwig A, Zong X, Jeglitsch M, Hofmann F, Biel M (1998) A family of hyperpolarization-activated mammalian cation channels. Nature 393:587-591.

Ludwig A, Budde T, Stieber J, Moosmang S, Wahl C, Holthoff K, Langebartels A, Wotjak C, Munsch T, Zong X, Feil S, Feil R, Lancel M, Chien KR, Konnerth A, Pape HC, Biel M, Hofmann F (2003) Absence epilepsy and sinus dysrhythmia in mice lacking the pacemaker channel HCN2. EMBO J 22:216-224.

Luthi A, McCormick DA (1998) H-current: properties of a neuronal and network pacemaker. Neuron 21:9-12.

Maccaferri G, McBain CJ (1996) The hyperpolarization-activated current (Ih) and its contribution to pacemaker activity in rat CA1 hippocampal stratum oriens-alveus interneurones. J Physiol (Lond) 497:119-130.

Maccaferri G, Mangoni M, Lazzari A, DiFrancesco D (1993) Properties of the hyperpolarization-activated current in rat hippocampal CA1 pyramidal cells. J Neurophysiol 69:2129-2136.

Magee JC (1998) Dendritic hyperpolarization-activated currents modify the integrative properties of hippocampal CA1 pyramidal neurons. J Neurosci 18:7613-7624.

Magee JC (1999) Dendritic Ih normalizes temporal summation in hippocampal CA1 neurons. Nat Neurosci 2:848.

Magill PJ, Bolam JP, Bevan MD (2001) Dopamine regulates the impact of the cerebral cortex on the subthalamic nucleus-globus pallidus network. Neuroscience 106:313-330.

Magnin M, Morel A, Jeanmonod D (2000) Single-unit analysis of the pallidum, thalamus and subthalamic nucleus in parkinsonian patients. Neuroscience 96:549-564.

Martin RL, Lee JH, Cribbs LL, Perez-Reyes E, Hanck DA (2000) Mibefradil block of cloned T-type calcium channels. J Pharmacol Exp Ther 295:302-308.

McCormick DA, Bal T (1997) Sleep and arousal: thalamocortical mechanisms. Annu Rev Neurosci 20:185-215.

McCormick DA, Pape HC (1990) Properties of a hyperpolarizationactivated cation current and its role in rhythmic oscillation in thalamic relay neurones. J Physiol (Lond) 431:291-318.

McDonough SI, Bean BP (1998) Mibefradil inhibition of T-type calcium channels in cerebellar Purkinje neurons. Mol Pharmacol 54:1080-1087.

Mercugliano M, Soghomonian JJ, Qin Y, Nguyen HQ, Feldblum S, Erlander 
MG, Tobin AJ, Chesselet MF (1992) Comparative distribution of messenger RNAs encoding glutamic acid decarboxylases (Mr 65,000 and $\mathrm{Mr}$ 67,000) in the basal ganglia of the rat. J Comp Neurol 318:245-254.

Millhouse OE (1986) Pallidal neurons in the rat. J Comp Neurol 254:209-227.

Monteggia LM, Eisch AJ, Tang MD, Kaczmarek LK, Nestler EJ (2000) Cloning and localization of the hyperpolarization-activated cyclic nucleotidegated channel family in rat brain. Brain Res Mol Brain Res 81:129-139.

Moosmang S, Stieber J, Zong X, Biel M, Hofmann F, Ludwig A (2001) Cellular expression and functional characterization of four hyperpolarizationactivated pacemaker channels in cardiac and neuronal tissues. Eur J Biochem 268:1646-1652.

Nakanishi H, Hori N, Kastuda N (1985) Neostriatal evoked inhibition and effects of dopamine on globus pallidal neurons in rat slice preparations. Brain Res 358:282-286.

Nambu A, Llinas R (1994) Electrophysiology of globus pallidus neurons in vitro. J Neurophysiol 72:1127-1139.

Nambu A, Llinas R (1997) Morphology of globus pallidus neurons: its correlation with electrophysiology in guinea pig brain slices. J Comp Neurol 377:85-94.

Neuhoff H, Neu A, Liss B, Roeper J (2002) I(h) channels contribute to the different functional properties of identified dopaminergic subpopulations in the midbrain. J Neurosci 22:1290-1302.

Nini A, Feingold A, Slovin H, Bergman H (1995) Neurons in the globus pallidus do not show correlated activity in the normal monkey, but phaselocked oscillations appear in the MPTP model of parkinsonism. J Neurophysiol 74:1800-1805.

Notomi T, Shigemoto R (2004) Immunohistochemical localization of Ih channel subunits, HCN1-4, in the rat brain. J Comp Neurol 471:241-276.

Oertel WH, Nitsch C, Mugnaini E (1984) Immunocytochemical demonstration of the GABA-ergic neurons in rat globus pallidus and nucleus entopeduncularis and their GABA-ergic innervation. Adv Neurol 40:91-98.

Pape HC (1996) Queer current and pacemaker: the hyperpolarizationactivated cation current in neurons. Annu Rev Physiol 58:299-327.

Parent A, Hazrati LN (1995) Functional anatomy of the basal ganglia. II. The place of subthalamic nucleus and external pallidum in basal ganglia circuitry. Brain Res Brain Res Rev 20:128-154

Park MR, Falls WM, Kitai ST (1982) An intracellular HRP study of the rat globus pallidus. I. Responses and light microscopic analysis. J Comp Neurol 211:284-294.

Perez-Reyes E (2003) Molecular physiology of low-voltage-activated t-type calcium channels. Physiol Rev 83:117-161.

Poisik OV, Mannaioni G, Traynelis S, Smith Y, Conn PJ (2003) Distinct functional roles of the metabotropic glutamate receptors 1 and 5 in the rat globus pallidus. J Neurosci 23:122-130.

Rajakumar N, Rushlow W, Naus CC, Elisevich K, Flumerfelt BA (1994) Neurochemical compartmentalization of the globus pallidus in the rat: an immunocytochemical study of calcium-binding proteins. J Comp Neurol 346:337-348

Raman IM, Bean BP (1999) Ionic currents underlying spontaneous action potentials in isolated cerebellar Purkinje neurons. J Neurosci 19:1663-1674.

Raz A, Vaadia E, Bergman H (2000) Firing patterns and correlations of spontaneous discharge of pallidal neurons in the normal and the tremulous 1-methyl-4-phenyl-1,2,3,6-tetrahydropyridine vervet model of parkinsonism. J Neurosci 20:8559-8571.

Raz A, Frechter-Mazar V, Feingold A, Abeles M, Vaadia E, Bergman H (2001) Activity of pallidal and striatal tonically active neurons is correlated in MPTP-treated monkeys but not in normal monkeys. J Neurosci 21:RC128(1-5).

Robinson RB, Siegelbaum SA (2003) Hyperpolarization-activated cation currents: from molecules to physiological function. Annu Rev Physiol 65:453-480.

Santoro B, Tibbs GR (1999) The HCN gene family: molecular basis of the hyperpolarization-activated pacemaker channels. Ann NY Acad Sci 868:741-764.

Santoro B, Liu DT, Yao H, Bartsch D, Kandel ER, Siegelbaum SA, Tibbs GR
(1998) Identification of a gene encoding a hyperpolarization-activated pacemaker channel of brain. Cell 93:717-729.

Santoro B, Chen S, Luthi A, Pavlidis P, Shumyatsky GP, Tibbs GR, Siegelbaum SA (2000) Molecular and functional heterogeneity of hyperpolarization-activated pacemaker channels in the mouse CNS. J Neurosci 20:5264-5275.

Sato F, Lavallee P, Levesque M, Parent A (2000) Single-axon tracing study of neurons of the external segment of the globus pallidus in primate. J Comp Neurol 417:17-31.

Shammah-Lagnado SJ, Alheid GF, Heimer L (1996) Efferent connections of the caudal part of the globus pallidus in the rat. J Comp Neurol 376:489-507.

Smith Y, Shink E, Sidibe M (1998) Neuronal circuitry and synaptic connectivity of the basal ganglia. Neurosurg Clin N Am 9:203-222.

Song WJ, Tkatch T, Baranauskas G, Ichinohe N, Kitai ST, Surmeier DJ (1998) Somatodendritic depolarization-activated potassium currents in rat neostriatal cholinergic interneurons are predominantly of the A type and attributable to coexpression of Kv4.2 and Kv4.1 subunits. J Neurosci 18:3124-3137.

Stanford IM (2003) Independent neuronal oscillators of the rat globus pallidus. J Neurophysiol 89:1713-1717.

Surmeier DJ, Seno N, Kitai ST (1994) Acutely isolated neurons of the rat globus pallidus exhibit four types of high-voltage-activated $\mathrm{Ca}^{2+}$ current. J Neurophysiol 71:1272-1280.

Surmeier DJ, Song WJ, Yan Z (1996) Coordinated expression of dopamine receptors in neostriatal medium spiny neurons. J Neurosci 16:6579-6591.

Taddese A, Bean BP (2002) Subthreshold sodium current from rapidly inactivating sodium channels drives spontaneous firing of tuberomammillary neurons. Neuron 33:587-600.

Talley EM, Cribbs LL, Lee JH, Daud A, Perez-Reyes E, Bayliss DA (1999) Differential distribution of three members of a gene family encoding low voltage-activated (T-type) calcium channels. J Neurosci 19:1895-1911.

Terman D, Rubin JE, Yew AC, Wilson CJ (2002) Activity patterns in a model for the subthalamopallidal network of the basal ganglia. J Neurosci 22:2963-2976.

Tkatch T, Baranauskas G, Surmeier DJ (1998) Basal forebrain neurons adjacent to the globus pallidus co-express GABAergic and cholinergic marker mRNAs. NeuroReport 9:1935-1939.

Tkatch T, Baranauskas G, Surmeier DJ (2000) Kv4.2 mRNA abundance and A-type $\mathrm{K}(+)$ current amplitude are linearly related in basal ganglia and basal forebrain neurons. J Neurosci 20:579-588.

Todorovic SM, Lingle CJ (1998) Pharmacological properties of T-type $\mathrm{Ca}^{2+}$ current in adult rat sensory neurons: effects of anticonvulsant and anesthetic agents. J Neurophysiol 79:240-252.

Ueno S, Bracamontes J, Zorumski C, Weiss DS, Steinbach JH (1997) Bicuculline and gabazine are allosteric inhibitors of channel opening of the $\mathrm{GABA}_{\mathrm{A}}$ receptor. J Neurosci 17:625-634.

Vitek JL (2002) Deep brain stimulation for Parkinson's disease. A critical re-evaluation of STN versus GPi DBS. Stereotact Funct Neurosurg 78:119-131.

Voorn P, van de Witte S, Tjon G, Jonker AJ (1999) Expression of enkephalin in pallido-striatal neurons. Ann NY Acad Sci 877:671-675.

Wang J, Chen S, Nolan MF, Siegelbaum SA (2002) Activity-dependent regulation of HCN pacemaker channels by cyclic AMP: signaling through dynamic allosteric coupling. Neuron 36:451-461.

Williams SR, Stuart GJ (2000) Site independence of EPSP time course is mediated by dendritic $\mathrm{I}(\mathrm{h})$ in neocortical pyramidal neurons. J Neurophysiol 83:3177-3182.

Williams SR, Stuart GJ (2003) Voltage- and site-dependent control of the somatic impact of dendritic IPSPs. J Neurosci 23:7358-7367.

Wolfart J, Roeper J (2002) Selective coupling of T-type calcium channels to SK potassium channels prevents intrinsic bursting in dopaminergic midbrain neurons. J Neurosci 22:3404-3413.

Yung WH, Hausser MA, Jack JJ (1991) Electrophysiology of dopaminergic and nondopaminergic neurones of the guinea-pig substantia nigra pars compacta in vitro. J Physiol (Lond) 436:643-667.

Zaborszky L, Pang K, Somogyi J, Nadasdy Z, Kallo I (1999) The basal forebrain corticopetal system revisited. Ann NY Acad Sci 877:339-367. 